\title{
Paridade e género: uma nova igualdade no desporto
}

\author{
Parity and gender: a new equality in sport \\ PATRÍCIA CARDOSO DIAS* \\ padias@autonoma.pt
}

GALILEU - REVISTA DE DIREITO E ECONOMIA - e-ISSN 2184-1845

Volume XXI $\cdot 1^{\text {st }}$ July Julho $-31^{\text {st }}$ December Dezembro $2020 \cdot$ pp. 95-143

DOI: https://doi.org/10.26619/2184-1845.XXI.2.6

Submitted on September $22^{\text {th }}, 2020$. Accepted on November $10^{\text {th }}, 2020$

Submetido em 22 de setembro, 2020. Aceite a 10 de novembro, 2020

RESUMO: A organização das competições desportivas encontra-se subordinada a um critério binário de género. Esta disposição é o reflexo heteronormativizado e hierarquizado socialmente construído que, conforme se verá, encontra respaldo na discursividade igualitária formal. A igualdade de género dita que se acautelem as diferenças que caraterizam a espécie humana, por oposição a um modelo persecutório de neutralidade que não assegura as diversas manifestações do exercício do direito fundamental à diferença que, em bom rigor, é expressão do princípio da igualdade material. A discriminação indireta que se infere do resultado eminentemente exclusivo e segregador das atletas transgénero femininas e com diferenças no desenvolvimento sexual é premissa para uma compreensão alargada do conceito de género e do papel fundamental que a paridade pode significar na concretização da igualdade material no âmbito das competições desportivas profissionais. A eliminação das categorias binárias desportivas, enformada pelo substrato da paridade para uma real igualdade de género com recurso a um sistema de handicap para determinação dos fatores relevantes em cada modalidade desportiva, é assim promotora de uma justiça distributiva meritocrática no desporto, promovendo simultaneamente a desconstrução misógina que subjaz ao padrão hetero binário socialmente instituído, que responde à preocupação das atletas transgénero femininas e com diferenças no desenvolvimento sexual apresentarem uma vantagem injusta em relação às atletas cisgénero.

PALAVRAS CHAVE: Género; Igualdade; Paridade; Transgénero.

\footnotetext{
* Mestre em Direito pela Universidade Autónoma de Lisboa "Luís de Camões". Doutoranda em Direito na Universidade Autónoma de Lisboa "Luís de Camões".
} 
ABSTRACT: The organization of sports competitions is subject to a binary gender criterion. This disposition is the heteronormatized and socially constructed hierarchical reflex that, as will be seen, finds support in formal egalitarian discourse. Gender equality dictates that the differences that characterize the human species be guarded against, as opposed to a persecutory model of neutrality that does not ensure the various manifestations of the exercise of the fundamental right to difference, which, strictly speaking, is an expression of the principle of material equality. The indirect discrimination that can be inferred from the eminently exclusive and segregating result of female transgender athletes and with differences in sexual development is a premise for a broader understanding of the concept of gender and the fundamental role that parity can play in the realization of material equality in the context of competitions professional sports. The elimination of binary sports categories, shaped by the substrate of parity for real gender equality using a handicap system to determine the relevant factors in each sport, is thus promoting meritocratic distributive justice in sport, while promoting deconstruction misogynist that underlies the socially instituted hetero binary pattern, which responds to the concern of female transgender athletes and with differences in sexual development, present an unfair advantage over cisgender athletes.

KEY WORDS: Gender; Equality; Parity; Transgender.

\section{INTRODUÇÃO}

A solução que se encontrar para a inclusão das atletas transgénero e com diferenças no desenvolvimento sexual nas competições desportivas irá definir nos enquanto sociedade. Será, de igual forma, o reflexo do Estado Democrático de Direito que reputamos harmonizado com o quadro multidimensional de proteção jurídica de direitos humanos.

O que carateriza a pessoa humana, na sua incomensurável diversidade, é a pertença à espécie humana. A natureza intrínseca da pessoa é a humanidade, é a pertença a esta espécie que não admitirá, a breve ou mais extenso trecho, a sua subordinação categorizada ou hierarquizada em todos os domínios fácticos em que se reflete o livre desenvolvimento da personalidade humana. A pessoa é, per se, liberdade. O livre exercício desta não carece pois de justificação. Justificadas terão de ser sim quaisquer restrições à projeção da pessoa.

Porque o sexo anatómico não determina a identidade pessoal, este tem assim de ser entendido no quadro do direito à identidade de género. Semelhante correspondência 
encerraria a pessoa humana a uma dimensão morfológica que desconsideraria a infinita diferença que ela própria encerra em si.

A emergência de um direito fundamental à diferença é, neste sentido, expressão da igualdade material que desconhece a hegemonia heteronormativa hierarquizada. Esta apenas é conhecida pelas construções sociais que a edificam e que são reproduzidas pela ordem normativa objetiva.

A igualdade que se procura alcançar necessariamente terá de atender aos destinatários ilimitadamente diversos na sua existência e convivência, consigo próprios e com os outros, atenta a natureza eminentemente social da pessoa, adensando-se a precisão de preservação da diferença.

O princípio da igualdade percorreu um longo e tortuoso caminho que conduziu ao reconhecimento da igualdade de género. Igualdade que ainda não se encontra verdadeiramente alcançada formal e materialmente, mas que convoca concomitantemente o reconhecimento de um direito à diferença, que deve ser integrado em políticas de direito anti discriminatório, e que necessariamente terá de adensar-se na sua matriz fundante de respeito social coletivo.

Compete ao Direito, em relação de reciprocidade com as demais áreas da ciência, conformar-se e acompanhar a evolução do conhecimento, oferecendo o seu manifesto contributo para a desconstrução das identidades heteronormativas.

O Direito e os direitos são os mesmos para todas as pessoas, são assexuados. O impulso legiferante em questões de género terá, assim, de criar ou recriar as condições necessárias para o exercício dos mesmos considerando esta matriz fundante que é génese dos direitos fundamentais da personalidade que, em bom rigor, são a razão de ser do Direito.

A concretização do princípio da dignidade da pessoa humana está assim intrinsecamente ligada aos mecanismos operativos do livre desenvolvimento da personalidade, do qual é expoente no objeto de análise deste texto o direito à identidade e autodeterminação de género.

O exercício concreto deste fundamental direito pode ter expressões materiais difusas, entre as quais o exercício do direito ao desporto e ao exercício físico, designadamente, no desporto profissional de competição que, em resultado eminentemente oposto ao que seria o paradigma de justiça desportiva, se tem evidenciado segregador para as atletas transgénero femininas e com diferenças no desenvolvimento sexual.

A proposta de reflexão subjacente ao texto é de eliminar as categorias de género binário nas competições desportivas, o que se impõe por força da própria tutela geral da personalidade, partindo da premissa de que a igualdade material de resultado é alcançada por via da atualização da interpretação da paridade, resultante de uma sincrónica e diacrónica 
adequação ao conceito de género no quadro de proteção dos direitos humanos contemporâneo.

Em ordem a alcançar o objetivo geral de justificar a eliminação das categorias binárias de género na organização das competições desportivas, partimos da necessária compreensão da humanidade assexuada e da incompatibilidade com o poder de autodeterminação que é a própria pessoa com a sua redução a um sexo pré-determinado e objetivo meramente morfológico.

Resulta, para este efeito, ser necessário legitimar o direito fundamental à identidade e autodeterminação pessoal de género, radicado do direito fundamental à diferença, à luz do contributo transdisciplinar científico que enforma as criações normativo-jurídicas.

Neste desiderato, o princípio da igualdade e a sua concretização não poderá ser conciliado com a estigmatização, segregação e desigualdade em resultados práticos, pelo que a igualdade formal e material não se poderá adstringir a instrumentos transitórios que não considerem a perpetuidade da espécie humana assexuada e infinitamente diversa.

Convoca-se, assim, a paridade enquanto nova forma de igualdade para acautelar a tutela diferenciada que urge ser reconhecida às atletas transgénero femininas e com diferenças no desenvolvimento sexual e que, concomitantemente, promoverá o desporto de competição a sede de verdadeira justiça inclusiva, porquanto permitirá de igual forma a elegibilidade de atletas de género não binário.

Na verdade, conforme se demonstrará, o tradicional argumento da testosterona, que até ao presente tem consistido no "melhor" argumento de discriminação indireta, não é aceitável à luz da sistemática dos direitos humanos fundamentais, porquanto não se poderá admitir que um/a atleta apenas possa competir se estiver em igualdade condições de perder a competição.

É a igual dignidade de todas as pessoas que determina que se reconheça a lotaria genética natural e o livre desenvolvimento da personalidade de género no desporto profissional de competição, que não se pode furtar, no âmbito de uma boa governança desportiva, ao cumprimento integral do desiderato do primado da pessoa humana.

É esta a razão de ser do Direito: proteção da pessoa e criação de condições para que se desenvolva livremente. Este paradigma poderá ser alcançado com a eliminação de categorias nas competições desportivas com recurso a um proporcional sistema de handicap que atenda às caraterísticas efetivamente relevantes para cada modalidade desportiva.

O modelo proposto poderá conduzir a que muitas competições, do ponto de vista do resultado, sejam organizadas binariamente, mas já não será este o kick off de origem, admitindo-se por esta via a participação de todo/as atletas de acordo com um modelo de meritocracia como impõe a própria verdade desportiva. 
A pessoa humana é muito mais que um corpo, é ser em devir, exige-se por isso ao Direito a conformação normativa com a dimensão ética, ontológica e axiológica da pessoa. Um verdadeiro Estado Democrático de Direito não autocompraz com uma igualdade meramente formal: a paridade é por isso uma das vias para a igualdade material nas questões de género.

\section{Da (des)construção da identidade jurídica de sexo bio-anatómico ao género: a crónica de uma humanidade sexuada}

O Direito, enquanto ordem objetiva, é o meio de produção e reprodução das construções sociais, é um fenómeno humano e social (daqui decorre o brocado latino ubi ius ibi societas) ${ }^{1}$.

Por conseguinte, o próprio Direito objetivo tem contribuído significativamente para a construção das relações de género heteronormativas, orientadas pelo pressuposto de sexo binário (feminino e masculino) que, tendencialmente, evidenciam uma assimetria social entre o homem e a mulher.

É, por isso, particularmente relevante a definição da UNESCO quanto ao género: «Gender roles and expectations are learned. They can change over time and they vary within and between cultures. Systems of social differentiation such as political status, class, ethnicity, physical and mental disability, age and more, modify gender roles. The concept of gender is vital because, applied to social analysis, it reveals how women's subordination (or men's domination) is socially constructed. As such, the subordination can be changed or ended. It is not biologically predetermined nor is it fixed forever» ${ }^{2}$.

A valoração endereçada à diferenciação na construção da identidade jurídica feminina e masculina promoveu a justificação clássica para o tratamento desigual das pessoas radicado na sua diferença biológica e anatómica ${ }^{3} 5$.

1 ASCENSÃO, José de Oliveira - O Direito. Introdução e Teoria Geral. Coimbra: Almedina, 2008, pp. 23-29.

2 UNESCO - Unesco's Gender Mainstreaming Implementation Framework for 2002-2007 - Basic Definitions of Key Concepts and Terms,p. 17.

3 Veja a este propósito a redação do art. $^{\circ} 1605 .^{\circ}$ do Código Civil, revogado recentemente pela Lei N. ${ }^{\circ}$ 85/2019, de 3 de setembro, que considerava lícito à mulher contrair novas núpcias passados cento e oitenta dias apenas, e se, obtivesse uma declaração judicial de que não se encontrava grávida ou que tivesse tido algum filho depois da dissolução, declaração de nulidade ou anulação do casamento anterior; se os cônjuges estivessem separados judicialmente de pessoas e bens e o casamento se dissolvesse por morte do marido, podia ainda a mulher celebrar segundo casamento decorridos cento e oitenta dias sobre a data em que transitou em julgado a sentença de separação, se obtivesse uma declaração judicial de que não se encontrasse grávida ou tivesse tido algum filho depois daquela data.

4 BELEZA, Teresa Pizarro - Direito das Mulheres e da Igualdade Social. A Construção Jurídica das Relações de Género. Coimbra: Edições Almedina, 2010, p. 88.

5 Vera Lúcia Raposo identifica três etapas fundamentais na compreensão dos conceitos de igualdade e desigualdade. Na primeira, relacionando-se a diferença com a desigualdade, operou-se uma verdadeira 
A heteronormatividade parte da premissa que homens e mulheres são intrinsecamente diferentes, encontrando-se, todavia, subjacente a esta conceção a tradicional prevalência do "homem" em relação à "mulher", devendo esta adaptar-se às regras de regime criadas sob a égide do padrão masculinizado ${ }^{6}$.

O paradigma igualitário, nas declarações que sobre o mesmo versam, fornecem artificialmente os termos de comparação da discursividade heteronormativa ${ }^{7}$ se não se apresentarem densificados por um critério de igualdade fáctica.

Em bom rigor, a discursividade igualitária formal das mais diversas áreas - v.g. jurídica $^{8}$, médica ${ }^{9}$, religiosa ${ }^{10}$ - reforça a criação de identidades normativas binárias, vislumbrando-se a estigmatização, mais ou menos velada, face às diversas perceções sociais e

hierarquização valorativa entre seres superiores e inferiores, entendendo-se, rectius, as mulheres como seres negativamente diferentes; na segunda, a igualdade relacionou-se com a identidade, passando a entender-se que todos tinham direito a ser tratados como iguais na exata medida em que cumprissem os critérios da identidade, realçando-se nesta fase as semelhanças entre as pessoas como forma de obstar às desigualdades suscitadas na primeira etapa; na terceira etapa a diferença assume-se como um fator correlativo com a igualdade, assumindose por princípio que todos gozam do direito a ser tratados de forma igual, proporcionalmente às suas diferenças, de forma a promover a realização de cada necessidade pessoal. Cfr. RAPOSO, Vera Lúcia Carapeto - «Paridade, a Outra Igualdade». In: Ciências Jurídicas Civilísticas: Comunitárias; Económicas; Empresariais; Filosóficas; Históricas; Políticas; Processuais. Coimbra: Edições Almedina, 2005,p. 572.

6 A hegemonia masculina no desporto, suportada por uma desigualdade socialmente construída, é em bom rigor tolerada conforme resulta da recessão crítica a Sex Segregation in Sports: Why Separate is Not Equal. «(...) a wrester [sic] in 2011 who refused to compete against a girl in a collegiate tournament; he did so purely based on her sex. Their question was, why would a male wrestler be applauded for refusing to compete against a woman, when would have been condemned for his choice were it based on race, sexual orientation, or nationality?». SAPPENFIELD, Kourtney - Adrienne Miller and Jomills Braddock II: Sex Segregation in Sports: Why Separate is Not Equal,p. 2479.

7 A igualdade de género é, assim, uma das prioridades globais da UNESCO, encontrando-se em curso o designado UNESCO Priority Gender Equality Action Plan for 2014-2021, cuja construção e garantia da igualdade de género como princípio de direitos humanos e fundamento da democracia, tem como objetivo o alcançar de uma igualdade substantiva (na vertente jurídica e de facto).

8 Aidentidade jurídica de acordo com o sexo bio anatómico é atribuída à nascença, conforme resulta das disposições conjugadas no $\mathrm{n} .{ }^{\circ} 1$ do art. ${ }^{\circ} 101 .^{\circ}-\mathrm{A}$ (requisitos gerais) e alínea b) do.$^{\circ} 1$ do art. ${ }^{\circ} 10 .^{\circ}$ (requisitos especiais), às quais acresce a exigência prevista na alínea a) do $\mathrm{n}^{\circ} 2$ do art. ${ }^{\circ} 103{ }^{\circ}{ }^{\circ}$ (todos do Código do Registo Civil) em relação à composição do nome próprio, que não deve suscitar dúvidas sobre o sexo do registando.

9 SCHWEND, Amets Suess - «Trans Health Care from a Despathologization and Human Rights Perspective». In: Public Health Reviews. Vol. 41, N. ${ }^{\circ}$ 3, (2020), pp. 2-3; «No geral, os médicos e alunos de medicina assumem que têm pouca ou nenhuma preparação no que concerne à abordagem em contexto clínico da orientação sexual e de assuntos relacionados com a identidade de género. (...). O facto de nos movimentarmos numa sociedade hétero e cisnormativa cria desigualdades importantes para todos aqueles que se sentem excluídos desta «normalidade». No contexto clínico o tema é tanto mais importante quanto pode condicionar o grau de exposição e de confiança do doente perante os profissionais de saúde, o que em última análise nos afasta de uma saúde centrada no doente e nos coloca perante uma situação de não respeito pelo princípio da equidade.». Cfr. MACEDO, Ana - Identidade de Género e Orientação Sexual na Prática Clínica. Lisboa: Edições Sílabo, 2018, pp. 66 e 68.

10 Em 2019 o Vaticano publicou um documento da Congregação para a Educação Católica, cujo título é "Homem e Mulher os Criou", cuja matriz antropológica cristã conservadora apela, naturalmente, à manutenção adstrita da identidade pessoal à diferença biológica entre masculino e feminino. Cfr. CONGREGAÇÃO para a Educação Católica - Homem e Mulher os Criou. 
culturais da diferença (v.g. raça, etnia, religião, hábitos de vida) entre seres humanos em relação à padronização do género feminino e masculino.

Com efeito, e não obstante a profícua promoção enquanto tarefa fundamental do Estado $^{11}$, o reforço da heteronormativização binária encontra imediatamente amparo nos fundamentos constitucionais na prossecução da igualdade entre homens e mulheres. A norma constitucional impõe, neste sentido, a eliminação de desigualdades formais e materiais por via do impulso legislativo, o que apenas se alcança com a continua densificação da igualdade de género enquanto vertente do princípio da igualdade.

Com Ana Macedo afirma-se que «Alargando este conceito podemos dizer que os padrões heteronormativos transcendem a orientação sexual e são também cisnormativos dado que incluem a identidade de género (cisgénero) e a definição binária de género, mesmo nas sociedades que se assumem como tolerantes e abertas à diversidade, quer em termos sociais quer em termos legais. $\gg^{12}$.

A hegemonia heteronormativa comporta, assim, duas consequências imediatas: a primeira, promove a discriminação por via da estigmatização daquilo que se afasta do padrão socialmente normalizado; a segunda, reifica a reprodução cíclica de padrões normalizados, determinando um "esforço acrescido" de (aparente) tolerância para com caraterísticas diferenciadas que não são incorporadas ab initio no desenvolvimento social e cultural da pessoa humana ${ }^{13}$.

As declarações sobre a igualdade são, nestes termos, estranhas à perceção da diferença constitutiva dessa mesma diferença, porquanto partem de uma homogeneidade binária heteronormativa dirigida a destinatários infinitamente diferentes ${ }^{14}$.

Com efeito, cremos que o "caminho a percorrer" pelo princípio da igualdade hodiernamente, implicará abandonar o tradicional paradigma igualitário de neutralidade (que atende particularmente ao que une as pessoas entre si e não ao que as separa), para se aproximar de um paradigma diferenciado, preservando a diferença, rectius, por via da criação de regimes jurídicos adequados à preservação das particularidades de cada ser humano.

Neste sentido, delineando uma política de direito anti discriminatório e visando salvaguardar o direito à autodeterminação pessoal com o consequente reconhecimento dos direitos dele decorrentes em relação às pessoas transgénero (tais como o reconhecimento

11 Alínea h) do n. ${ }^{\circ} 1$ do art. ${ }^{\circ} 9 .^{\circ}$ da Constituição da República Portuguesa.

12 MACEDO, Ana - Identidade de Género e Orientação ..., p. 65.

13 «A heteronormatividade pressupõe uma visão do mundo na qual há padrões clássicos de feminino e masculino e onde a orientação sexual de referência é a heterossexual, sendo a relação e tratamento das pessoas homossexuais adaptado daquilo que é assumido para as pessoas heterossexuais.». Cfr. MACEDO, Ana - Identidade de Género e Orientação ..., p. . 65.

14 BELEZA, Teresa Pizarro - Direito das Mulheres e da Igualdade Social..., pp. 90-91. 
da sua identidade de género e o direito a ser tratada e identificada de acordo com ela), a Resolução 2048 do Conselho Europeu de 2015 recomendava que cada Estado Membro ponderasse o desenvolvimento de procedimentos céleres e transparentes em relação ao procedimento de mudança de menção de sexo e nome próprio no registo civil, a eliminação de requisitos prévios quanto à esterilização ou quaisquer outros tratamentos médicos de afirmação de género, diagnósticos de saúde mental ou a possibilidade de inclusão de um terceiro género nos documentos de identificação daqueles que assim o desejassem ${ }^{15}{ }^{16}$.

Não é, nestes termos, de estranhar que um direito fundamental à diferença venha a ganhar expressão reforçada em alguns ordenamentos jurídicos, designadamente, no que concerne ao direito à autodeterminação da identidade e expressão de género e do direito à proteção das caraterísticas sexuais ${ }^{17}$ que, com a inerente garantia jurídica, assegura que a pessoa não abdique de o ser em liberdade e de se transformar naquilo que é ou naquilo que vai sendo.

Nem todos os seres humanos, atendendo ao conhecimento científico de outras áreas, são necessariamente homens e mulheres enquadrados em categorias objetivas e pré-determinadas ${ }^{18}$, tratando-se de um fenómeno humano comum e culturalmente diverso.

Assinala-se assim o potencial e pertinência das normas, particularmente as constitucionais, na construção da perceção coletiva da igualdade de género, assegurando um direito à diferença, enquanto dimensões fundamentais do princípio da igualdade.

Na verdade, é a experiência histórica que demonstra que a proclamação e a consagração constitucional do princípio da igualdade dependem da realidade constitucional vivenciada em cada cultura cívica, pelo que a sua realização legislativa e aplicação prática padecem das refrações decorrentes do âmbito social e valores pré adquiridos.

Daqui resulta a importância da precisão dos conceitos. Os conceitos, ainda que não consolidados ou suscetíveis de reformulação, exercem a pertinente função de conduzir o pensamento, indicando de igual forma a realidade social e valores que "observam" para a sua construção.

15 CONSELHO Europeu - Recomendação 2048.

$16 \mathrm{Na}$ Nova Zelândia, nos casos em que não é possível determinar o sexo à nascença, o registo civil prevê a possibilidade de inscrição com "sexo indeterminado", sendo que em 2012 foi incluída a designação "X" nos documentos de identificação de pessoas em processo de afirmação de género; na Austrália, desde 2003, é possível a designação de género "X" para todas as pessoas adultas e não só para pessoas com sexo indeterminado; na Alemanha, em 2017, o Tribunal Constitucional pronunciou-se quanto à existência de um terceiro género, decidindo que o registo civil e a identidade civil apenas são expressão da identidade pessoal se coincidirem entre si, pelo que o terceiro género é baseado na identidade pessoal e não no sexo biológico.

17 A título de exemplo, em Portugal, a LEI N. ${ }^{\circ}$ 38/2018, de 7 de agosto, que estabelece o direito à autodeterminação da identidade de género e expressão de género e o direito à proteção das caraterísticas sexuais de cada pessoa.

18 Neste mesmo sentido a WORLD Professional Association for Transgender Health - Standarts of Care for the Health of Transsexual, Transgender, and Gender-Nonconforming People, pp. 4-5. 


\section{Relevância do rigor terminológico: sexo, género, identidade de género, transgénero}

A igualdade, abstrata e concreta, não se tem alcançado da mera consagração constitucional enquanto princípio, mas do equilíbrio que vem sendo encontrado entre a justiça concreta e o direito à diferença que resultou reconhecido por via das lutas travadas pela igualdade por aqueles que se encontravam (ou encontram) marginalizados.

Se, como refere Jorge Miranda, os direitos são os mesmos para todos, mas nem todos se encontram em igualdade de condições para os exercer «(...) é preciso que essas condições sejam criadas ou recriadas através da transformação da vida e das estruturas dentro das quais as pessoas se movem» ${ }^{19}$.

A criação ou recriação destas condições, no desiderato da equidade para o exercício de direitos que se prossegue na ponderação da (re)construção do género no desporto encontra, necessariamente, a sua matriz fundante no rigor terminológico que se alcança transdisciplinarmente das ciências médica, ética, sociológica e jurídica.

É o complexo destas áreas do conhecimento que permitem o desenvolvimento da capacidade individual e coletiva anti discriminatória ${ }^{20}$ - conceito elástico e mutável, que varia diacronicamente e sincronicamente - minorando-se a conhecida clivagem intolerante em relação ao transgenismo.

O sexo, feminino e masculino, é o resultado expresso da observação dos órgãos sexuais externos $^{21}$ (caraterísticas sexuais primárias). É definido de acordo com as caraterísticas biológicas, anatómicas, genéticas e reprodutivas da pessoa. Neste sentido, regra geral, o cariótipo consistente com o sexo feminino apresenta-se com a designação 46 XX e o masculino $46 \mathrm{XY}^{22}$.

19 MIRANDA, Jorge - Manual de Direito Constitucional. Tomo IV. Direitos Fundamentais. $4{ }^{\text {a }}$ Edição. Coimbra: Coimbra Editora, 2008, p. 241.

20 O direito anti discriminatório é aplicável em diversas situações, como seja o ingresso em estabelecimento de ensino ou no mercado de trabalho, relevando de igual forma neste domínio que particularmente nos interessa agora analisar. Originariamente o conceito de discriminação significava distinguir ou diferenciar de forma neutra. Hodiernamente é expressão de intolerância, associada a preconceitos e conotações pejorativas, significando o discriminar uma diferenciação negativa. RAPOSO, Vera Lúcia - O Poder de Eva. O Princípio da Igualdade no Âmbito dos Direitos Políticos; Problemas Suscitados pela Discriminação Positiva. Coimbra: Edições Almedina, 2004, pp. . 291-299.

21 Seja no momento do nascimento, seja em momento anterior através dos meios de diagnóstico pré-natal.

22 HIRSCHBERG, Angelica Lindén - Female Hyperandrogenism and elite sports. Endocrine Connections Review. P. 84-85; Contudo, existem composições cromossomáticas inferiores a 46, tais como as pessoas diagnosticadas com a Síndrome de Turner, cuja variação consiste num cariótipo $45 \mathrm{XO}$, bem como composições superiores a 46, como é o caso da Síndrome de Klinefelter em que o cariótipo é 47 XXY. Cfr. SCHULTZ, Jamie - «Caster Semenya and the "Question of Too": Sex Testing in Elite Women's Sport and the Issue of Advantage». In: Quest. N. ${ }^{\circ} 63$, (2011), pp. 230-231. 
A este propósito cumpre convocar as situações de diferenças no desenvolvimento sexual (DDS ${ }^{23}$, nas quais se enquadram as pessoas que apresentam variações na anatomia das caraterísticas sexuais primárias e secundárias, inicialmente designadas hermafroditas, posteriormente intersexo ${ }^{24}$. As DDS compreendem assim atipicidades do sexo morfológico, bem como situações congénitas respeitantes ao desenvolvimento cromossómico e das gónadas (ovários e testículos) ${ }^{25}$.

Se uma atipicidade da anatomia das caraterísticas sexuais primárias externas é relativamente apreensível, o mesmo não se poderá afirmar em relação às demais DDS cujas variações podem consistir em alterações cromossómicas e hormonais.

Com efeito, algumas mulheres e homens nascem com diferenças no desenvolvimento sexual, diagnóstico que tanto se pode verificar precocemente à nascença ou na infância, como na adolescência ou durante a vida adulta. A forma de apresentação precoce resulta, regra geral, de casos de ambiguidade genital, mas pode ser observada em apresentações tardias variáveis ${ }^{26}$.

A DDS de desconformidade do fenótipo e de cariótipo masculino $46 \mathrm{XY}$ de gónadas não descendentes, mas funcionais, na correspondência com o sexo morfológico feminino podem, assim, resultar de variações cromossomáticas e hormonais que determinam um nível de produção endógena de testosterona idêntica à das pessoas com morfologia humana masculina não diagnosticadas com DDS. Neste caso, se os recetores de androgénio forem funcionais, o desenvolvimento da massa muscular, da glândula mamária, a alteração da voz ou a distribuição da gordura corporal tornar-se-ão semelhantes aos verifi-

23 Esta nomenclatura sucedeu a diversos termos que, além de pouco precisos cientificamente, socialmente eram alvo de associações pejorativas, tais como pseudo-hermafroditas, sexo reverso, intersexo. Cfr. LEE, Peter A., HOUK, Christopher P., AHMED, S. Faisal; [et. al.] - «Consensus Statement on Management of Intersex Disorders. Pediatrics». In: Pediatrics. N. ${ }^{118}$, (2006), p. 488. Inerente a todas as ciências é a evolução diacrónica pelo que desde 2016 se tem vindo a discutir a adoção de um termo médico que reflita as sensibilidades das pessoas com DDS, flexível para receber e conformar-se com os resultados dos estudos que se vão desenvolvendo e que simultaneamente contribua para a consolidação do conhecimento científico nesta área. Cfr. LEE, Peter A.; NORDENSTRÖM, Arlene; HOUK, P. Christopher P. - «Global Disorders of Sex Development Update since 2006: Perceptions, Approach and Care». In: Hormone Research in Pediatrics. N. ${ }^{\circ} 85 / 3$, (2016), pp. 159-160.

24 «Em termos de desenvolvimento sexual ao nível biológico a maioria das pessoas nasce com uma anatomia e fisiologia típica de sexo feminino ou de sexo masculino. No entanto, cerca de $1 \%$ das pessoas nasce com características atípicas, seja ao nível genético, ao nível dos órgãos sexuais ou do desenvolvimento das gónadas». Cfr. MACEDO, Ana - Identidade de Género e Orientação ..., pp. 22 e 73; Em relação à especificidade das pessoas intersexo a nível cromossomático, cfr. SAX, Leonard - «How Common is Intersex? A Response to Anne FaustoSterling». In: The Journal of Sex Research. Vol. 39, N. $^{\circ} 3$.

25 HIRSCHBERG, Angelica Lindén - «Female Hyperandrogenism and elite sports». In: Endocrine Connections Review. N. ${ }^{\circ}$ 9. (2020), p. 83.

26 MACEDO, Ana - Identidade de Género e Orientação ..., p. 77. 
cados num corpo humano masculino, pese embora o fenótipo se identifique com o género feminino 27 .

Outra tipologia de DDS a ser considerada é a provocada pela deficiência da enzima $5 \alpha$-reductase do tipo 2 , resultante de uma mutação cromossomática que não permite a transformação da testosterona em di-hidrotestosterona. Neste caso, ainda que se verifique a presença de gónadas não descendentes, bem como a produção de níveis de testosterona comuns num corpo morfologicamente masculino sem DDS, atento o não desenvolvimento do órgão sexual masculino por força da deficiência enzimática, a identificação tem por referência o género feminino ${ }^{28}$.

Em ambos os casos de DDS, indivíduos morfologicamente femininos, revelam uma virilização progressiva que pode ser mais ou menos acentuada.

Há ainda que considerar a síndrome de insensibilidade ao androgénio que pode ser total $\left(\right.$ CAIS $^{29}$ ) ou parcial (PAIS $\left.{ }^{30}\right)$. Esta é causada por uma mutação do gene recetor de androgénio no cromossoma $X$, que determina em grau diverso a acentuação da virilização nas pessoas com cromossoma XY. Nos casos de insensibilidade total, ainda que se identifiquem gónadas não descendentes e níveis de testosterona considerados regulares num corpo humano masculino médio, a ausência de resposta androgénica determina um diminuto nível de virilização, identificando-se o indivíduo regularmente por referência ao género feminino; já nos casos de insensibilidade parcial, o desenvolvimento do fenótipo poderá variar, pelo que poder-se-ão observar indivíduos do género feminino mais masculinizadas e indivíduos do género feminino mais efeminados ${ }^{31}$.

Os casos descritos não podem ser confundidos com situações de não conformidade de género. Em bom rigor, o denominador comum que se encontra para a não conformidade de género e as diferenças no desenvolvimento sexual é apenas a ausência de fatores exógenos.

27 HIRSCHBERG, Angelica Lindén - «Female Hyperandrogenism ...». In: Endocrine Connections Review, p. 84.

28 HIRSCHBERG, Angelica Lindén - «Female Hyperandrogenism ...». In: Endocrine Connections Review, pp. 84-85; Mutação cromossomática relevante é também a observável na ineptidão da conversão da androstenediona em testosterona em resultado do défice apresentado na enzima 17 $\beta$-hidroxisteroide desidrogenase do tipo 3. Nestes casos a morfologia externa é variável, sendo que tipicamente estes indivíduos são cromossomaticamente XY, mas apenas durante a puberdade, com a produção endógena mais acentuada de androgénio se processa a progressão, ou não, da virilização, não obstante ser-lhes comumente atribuído o género feminino à nascença.

29 Síndrome de insensibilidade completa aos androgénios.

30 Síndrome de insensibilidade parcial aos androgénios.

31 Diagnosticada com esta condição médica foi a atleta espanhola María José Martínez-Patiño cuja anatomia corporal, órgãos sexuais primários e identidade de género eram tipicamente femininas, mas que geneticamente foi considerada um homem, porquanto o cariótipo cromossomático identificado foi 46XY. Cfr. SCHULTZ, Jamie - «Caster Semenya and the "Question of Too": Sex Testing in Elite Women's Sport and the Issue of Advantage», In: Quest, p. 234; HIRSCHBERG, Angelica Lindén - «Female Hyperandrogenism ...». In: Endocrine Connections Review, p. 84. 
As diferenças no desenvolvimento sexual definem-se como situações congénitas nas quais o desenvolvimento cromossomático, das gónadas ou da anatomia morfológica sexual é atípica.

A identidade de género corresponde ao género com o qual a pessoa se identifica, radicando de uma vivência eminentemente interna e individual, e através da qual se expressa, ou não, diariamente (expressão de género, por exemplo, através da roupa, do corte de cabelo, dos desportos praticados, comportamentos) ${ }^{32} 33$.

Esclarecendo «A identidade de género é definida pelo sentimento próprio e subjetivo relativamente a pretender um determinado género para si próprio (...). Em termos de identidade de género um indivíduo pode assumir-se como feminino ou masculino, no espetro feminino ou no espetro masculino, ou genderqueer. As pessoas podem assumir uma identidade de género indefinida, uma identidade que se sobrepõe ao género masculino e feminino, uma identidade sem um género ou terem uma identidade de género fluida, que se movimenta através do espetro do género, num contínuo entre o feminino e o masculino»34353637.

32 O acrónimo LGBTQI integra uma diversidade de indivíduos e de manifestações de personalidade, incluindo populações cuja identidade se baseia na orientação sexual e na identidade de género, compreendendo atualmente as pessoas intersexo e gender queer.

33 «La cualidad de trans, que las/os diferencia de mujeres y varones cis, consiste en la falta de correspondência entre el género autopercibido y el assignado conforme a la anatomia genital en el nacimiento (...). Para las/ os entrevistadas/os el género de una persona puede ser feminino o masculino, pero esto depende de la autopercepción de cada individuo y no de la anatomia genital. La presencia de genitales que no se corresponden com el género autopercibido, así como el haber realizado una transición desde el género assignado hacia el autopercibido, sólo cualifican el género de un individuo como «trans»». Cf. GODOY, Gabriel César - «La Identidad de Género Trans: Una Construcción Relacional y Contextualizada (San Luiz, Argentina, 2013-2015)». In: Athenea Digital. ISSN 1578-8946. Vol. 19, N. ${ }^{\circ}$ 3, (2019), p. 10.

34 ««Gender has been described as a person's internal sense of "gendered self" and place in the world. Gender differs from physiological sex traits and is not defined by external genitalia. Rather, gender is a construct of an individual's own gender identity.». BASS, Megan; GOZALEZ, Luis J.; COLIP, Leslie; [et. al] - «Rethinking Gender: The Nonbinary Approach». In: AM J Health-Syst Pharm. [sl]. Vol. 75, N. ${ }^{\circ} 22$, (2018), p. 1821.

35 MACEDO, Ana - Identidade de Género e Orientação ..., p. 21.

36 Espectro de género é a classificação que considera que o género se estabelece num continuo entre feminino e masculino, opondo-se à classificação binária, é comummente designada género fluido ou queergender; a pessoa que se defina como não tendo género ou de género neutro designa-se agénero, tratando-se de uma forma de identidade de género não binária; a disforia de género consiste no diagnóstico DSM-5 atribuído a pessoas cuja identidade de género não corresponde ao sexo e género atribuídos à nascença provocando sofrimento ou desconforto causado por aquela discordância. BASS, Megan; GOZALEZ, Luis J.; COLIP, Leslie; [et. al] «Rethinking Gender: The Nonbinary Approach». In: AM J Health-Syst Pharm. [sl]. Vol. 75, N. ${ }^{\circ} 22$, (2018), p. 1821; MACEDO, Ana - Identidade de Género e Orientação ..., p. 43.

37 Sustentando que a identidade de género transgénero consiste numa construção relacional, que requer um trabalho consistente e permanente de auto perceção e que se encontra socioculturalmente condicionada, por oposição à concetualização da identidade de género transgénero enquanto produção e processo volitivo eminentemente pessoal, conferir GODOY, Gabriel César - «La Identidad de Género Trans: Una Construcción Relacional y Contextualizada (San Luiz, Argentina, 2013-2015)». In: Athenea Digital. Vol. 19, N. ${ }^{\circ}$ 3, (2019). 
Designam-se cisgénero as pessoas que se identificam com a categoria de género que corresponde às caraterísticas anatómicas sexuais que determinaram a especificação do sexo no modelo binário ${ }^{38}$.

Já o termo transgénero é empregue para descrever diversas identidades e expressões de género que não se identificam com as caraterísticas biológicas visíveis, não se conformando com o estereotipo social de homem e mulher ${ }^{39}$, não sendo relevante a pessoa ter iniciado ou pretender iniciar o processo de transição ou cirurgia de afirmação de género.

$O$ adjetivo transsexual, que na verdade consiste numa designação desadequada porque muitas pessoas não experimentam um processo de transição porque nunca reputaram para si o género consignado à nascença, refere-se às pessoas transgénero feminino ou masculino que tenham realizado tratamento hormonal ou cirúrgico de afirmação de género.

Os procedimentos médicos de afirmação de género estão assim vocacionados para pessoas com identidade de género diferente do sexo atribuído à nascença, mas com identidade binária, pelo que os tratamentos (alguns reversíveis e outros irreversíveis) prosseguem alcançar as caraterísticas sexuais primárias e secundárias do género com o qual a pessoa se identifica ${ }^{40}$.

Por conseguinte, importa ter presente que a pessoa transgénero não tem necessariamente de experimentar um processo de afirmação de género ${ }^{41}$ com recurso a terapias hormonais ou intervenções cirúrgicas ${ }^{42}$, o que é aliás reforçado com o reconhecimento de identidades de género não binárias.

O género pode ser definido como o conjunto de caraterísticas psicológicas, sociais, culturais e comportamentais normalmente associadas ao sexo anatómico feminino ou masculino ${ }^{43}$.

38 BIANCHI, Andria - Something Got to Give: Reconsidering the Justification for a Gender Divide in Sport. In: Philosophies. [sl]. Vol. 4, N. ${ }^{\circ} 23,(2019) . p .2$.

39 «A transgender person identifies with a gender that differs from their sex, where a person's sex is usually assigned at birth and based on factor such as hormones and reproductive systems». BIANCHI, Andria «Something Got to Give: Reconsidering the Justification for a Gender Divide in Sport». In: Philosophies, p. 2.

40 WORLD Professional Association for Transgender Health - Standarts of Care for the Health of Transsexual, Transgender, and Gender-Nonconforming People, pp. 12-25, 37-52.

41 SCHWEND, Amets Suess - «Trans Health Care from a Despathologization and Human Rights Perspective». In: Public Health Reviews. Vol. 41, N. ${ }^{\circ}$ 3, (2020), p. 6.

42 WORLD Professional Association for Transgender Health - Standarts of Care for the Health of Transsexual, Transgender, and Gender-Nonconforming People, pp. 9-11.

43 «Gender refers to the roles and responsibilities of men and women that are created in our families, our societies and our cultures.The concept of gender also includes the expectations held about the characteristics, aptitudes and likely behaviours of both women and men (femininity and masculinity).». Cfr. UNESCO - Unesco's Gender Mainstreaming Implementation Framework for 2002-2007 - Basic Definitions of Key Concepts and Terms, p. 17. 
Concretizando, por um lado «O género é composto pela identidade individual, pela expressão dessa identidade e pela forma como tanto a identidade auto percecionada como a sua expressão se relacionam com os papéis de género tradicionais de cada sociedade», por outro lado, o sexo biológico (coordenado com a anatomia visível), atribuído à nascença, respeita ao corpo e à componente genética que o integra ${ }^{44}$.

Encontra-se por isso alguma imprecisão em António Menezes Cordeiro ao afirmar que «O ser humano é uma espécie sexuada. Os indivíduos de cada um dos sexos distinguem-se, fácil e imediatamente, pelo aspecto geral, pela postura, pelos gestos. (...) A diferenciação dos sexos constitui um dos grandes sortilégios da humanidade» ${ }^{45}$, atenta a adstrição ao facto anatómico que revela.

Não é líquido que os indivíduos de cada sexo se distingam fácil e imediatamente, tratando-se por isso de uma afirmação imprecisa que não corresponde à realidade fáctica, porquanto a frequente associação entre a não conformidade de género e a cirurgia de afirmação de género não se verifica em todas as pessoas. Na verdade, esta associação resulta de uma padronização binária da medicina que estabelece uma associação entre o corpo e o sexo anatómico, desconsiderando as diversas opções quanto ao corpo no qual a não conformidade de género se vivência, e que parece não atender à fluidez do espectro de género ${ }^{46}$.

A cirurgia de afirmação de género, com a inerente alteração das caraterísticas sexuais primárias e secundárias, bem como as terapias hormonais, consistem em procedimentos médicos enquadrados, não raras vezes, no âmbito do diagnóstico da disforia de género ${ }^{47}$, que nem sempre são observados em todas as pessoas transgénero ${ }^{48}$, uma vez que consis-

44 MACEDO, Ana - Identidade de Género e Orientação Sexual na Prática Clínica. P. 19, 43; Em relação aos conceitos de sexo e género ver também BELEZA, Teresa Pizarro - Direito das Mulheres e da Igualdade Social..., pp. 63-66.

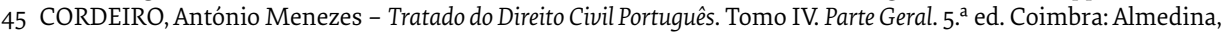
2019, p. 417.

46 SCHWEND, Amets Suess - «Trans Health Care from a Despathologization and Human Rights Perspective». In: Public Health Reviews, p. 6.

47 «Gender dysphoria involves a conflict between a person's physical or assigned gender and the gender with which he/she/they identify. People with gender dysphoria may be very uncomfortable with the gender they were assigned, sometimes described as being uncomfortable with their body (particularly developments during puberty) or being uncomfortable with the expected roles of their assigned gender.

People with gender dysphoria may often experience significant distress and/or problems functioning associated with this conflict between the way they feel and think of themselves (referred to as experienced or expressed gender) and their physical or assigned gender». Cfr. AMERICAN Psychiatric Association - Help With Gender Dysphoria.

48 WORLD Professional Association for Transgender Health - Standarts of Care for the Health of Transsexual, Transgender, and Gender-Nonconforming People, pp. 8-9. 
tem em cuidados de saúde que podem ser adotados de forma individualizada ou em conjunto de acordo com o destinatário concreto dos mesmos ${ }^{49}$.

Esta hegemonia conceptual acentuadamente binária encontra-se de igual forma em Mafalda Miranda Barbosa que, aparentemente, tolerando específicas "situações patológicas" de não conformidade de género, não admite o reconhecimento pelo ordenamento jurídico do direito à identidade de género como parte integrante do direito ao livre desenvolvimento da personalidade, sustentando, num raciocínio que se tem por necessariamente equivocado, que «(...) um direito à autodeterminação e à identidade de género conduz à destruição da pessoa, (...) o suposto direito (...) que se invoca (apenas alicerçado num querer arbitrário) inexiste» ${ }^{50}$.

Parece neste argumento ficar quedado ao esquecimento o árduo caminho percorrido pela despatologização do transgenismo, rectius do transsexualismo, particularmente na última década, que conduziu a uma alteração do modelo de cuidados de saúde e da conformação jurídico-normativa que se exige em relação às pessoas transgénero.

A premência da criação de um quadro internacional de princípios ético orientadores de um plano de proteção multidimensinal de direitos humanos fundamentais respeitantes à orientação sexual, identidade e expressão de género e salvaguarda das caraterísticas sexuais, determinou a adoção de instrumento de soft law, The Yogykarta Principles ${ }^{51}$, considerando o profícuo contributo que um quadro de proteção ético-legal apresenta para a desconstrução dos preconceitos culturalmente instituídos e para a despatolização da não conformidade de género ${ }^{52}$.

49 «Gender-affirmative health care can include any single or combination of a number of social, psychological, behavioural or medical (including hormonal treatment or surgery) interventions designed to support and affirm an individual's gender identity». Cfr. WORLD Health Organization - WHO/Europe brief - transgender health in the context of ICD-11; Não obstante a remoção do catálogo de transtornos mentais na 10. ${ }^{\mathrm{a}}$ edição do ICD, o processo de afirmação de género figura ainda como transtorno de saúde mental no DSM-5 da American Psychiatric Association; SCHWEND, Amets Suess - Trans Health Care from a Despathologization and Human Rights Perspective. Public Health Reviews, pp. 2, 9; Em sentido próximo, mas não totalmente coincidente, mas reforçando a dissociação entre a incongruência de género e a cirurgia de afirmação de género Sharon Cowan refere que «Forcing subjects to live in a binary and dichotomous sex and gender system leads to a discourse of "mistakes". Developing a legal and social framework that does not attempt to "freeze" sex and gender, is the only way to recognise the complexity of sexual subjectivity». Cfr. COWAN, Sharon - «"Gender is No Substitute for Sex": A Comparative Human Rights Analysis of the Legal Regulation of Sexual Identity». In: Feminist Legal Studies. N. ${ }^{\circ} 13$, (2005), p. 93.

50 BARBOSA, Mafalda Miranda e ÁLVAREZ, Tomás Prieto - O Direito ao Livre Desenvolvimento da Personalidade. Coimbra: GestLegal, 2020, pp. 111 e 114. Admitem, contudo, o reconhecimento de um direito à identidade sexual em casos muito particulares.

51 The Yogykarta Principles foi adotada em 2007, a última atualização verificou-se em 2017, sendo conhecida como The Yogykarta Principles Plus 10.

52 SCHWEND, Amets Suess - «Trans Health Care from a Despathologization and Human Rights Perspective». In: Public Health Reviews, pp. 3-4. 
Sob este propósito, a incongruência de género constava do capítulo reservado às patologias de saúde mental e comportamentais do International Classification of Diseases (ICD) desde 1975, todavia em 2018 transitou para o capítulo de condições relacionadas com a saúde sexual ${ }^{53}$, promovendo a diminuição do estigma associado a um grupo de pessoas que enformam uma população diversificada e não inerentemente doente.

O sexo, enquanto elemento biológico determinado e objetivo foi ultrapassado pela construção sociológica de género. Reclama-se por isso a intervenção do ordenamento jurídico, não apenas a título residual, mas a título constitutivo do acolhimento de uma perspetiva não binária do sexo e do género de acordo com a auto perceção da pessoa sobre si mesma.

A igualdade de género não pode assim ser reduzida a uma igualdade morfologicamente sexuada. A sua proclamação e alcance material exige, assim, que se considere a diversidade de género, sendo esta a única via de cumprimento substantivo do primado da pessoa humana, referencial ético e axiológico da dignidade que lhe é imanente.

O apanágio da igualdade aplicada ao género, no seu sentido primário, cumpre a sua finalidade enquanto não sustentar a estigmatização, a segregação e a desigualdade. Ora, pessoas transgénero são expostas a reiteradas violações da sua integridade que radicam dos padrões heteronormativos instituídos, pelo que se impõe o reconhecimento e consagração da existência de outras manifestações do reduto último de privacidade da pessoa humana e livre desenvolvimento da sua personalidade para além do artificial dualismo sexuado.

O conceito de igualdade de género terá assim de evoluir e adaptar-se sincronicamente ao conceito de género, harmonizado com o reconhecimento da diversidade e expressão de género enquanto direito humano e do qual radica uma dimensão protetiva que desloca a perspetiva muito adstrita à pessoa sexuada para o repúdio dos comportamentos sociais e culturalmente construídos discriminadores da diferença individual em que consiste a pessoa ser em devir.

\section{Do direito à identidade pessoal ao direito à autodeterminação de género: anatomia assexuada do direito matriz ao livre desenvolvimento da personalidade humana}

O direito à identidade pessoal enquanto garantia de identificação de cada pessoa como indivíduo, singular e irrepetível, não deve deixar de ser interpretado em harmonia com o 
direito ao livre desenvolvimento da personalidade, enquanto manifestação da dignidade intrínseca que é reconhecida à pessoa humana.

A dignidade da pessoa humana, valor anterior à própria ideia de Estado de Direito Democrático, é por isso referencial primário de direitos fundamentais que lhe asseguram uma expressão mais definida.

A consagração constitucional do direito ao livre desenvolvimento da personalidade ${ }^{54}$ representa sobretudo a consagração de um direito à liberdade da pessoa em relação à sua individualidade, donde no bem jurídico tutelado necessariamente se encontram as diferenças dessa individualidade ${ }^{55}$.

Não se cinge, contudo, à dimensão individual da diferença, porquanto lhe é inerente uma dimensão social que resulta de uma interação com as outras pessoas. A natureza social do desenvolvimento da personalidade exige, assim, o estabelecimento de um quadro normativo que materialize as condições de desenvolvimento da personalidade, não se bastando enquanto garantia de não ingerência na liberdade individual de estabelecimento de diferenças, mas sobretudo enquanto exigência ao legislador de tutela da integridade da liberdade geral de ação da pessoa ${ }^{56}$ consistente com a garantia de desenvolvimento de uma individualidade autónoma e livre.

O princípio geral de respeito pela dignidade da pessoa humana e desenvolvimento da sua personalidade são por isso a sede fundamental do direito geral de personalidade que assegura uma proteção absoluta da pessoa, proteção que se opera não apenas por via da tutela da personalidade, mas também da realização efetiva da personalidade.

O direito geral de personalidade é, assim, um direito à pessoa no seu todo, «(...) não apenas como ser mas como ser em devir e, por consequência, no seu próprio poder de autodeterminação (...) $>^{57}$, um verdadeiro direito à liberdade e à existência, atenta a sua dimensão dinâmica (não estática), inesgotável e ilimitável. A ilimitabilidade e inesgotabilidade da personalidade exigem, desta forma, a garantia de condições essenciais para que o indivíduo seja verdadeiramente pessoa, que não se auto comprazem apenas com o direito geral de personalidade e os direitos especiais da personalidade ${ }^{58}$ enquanto mecanismos operativos dos direitos fundamentais.

54 N. ${ }^{\circ} 1$ do artigo $26 .^{\circ}$ da Constituição da República Portuguesa.

55 PINTO, Paulo da Mota - Direitos de Personalidade e Direitos Fundamentais - Estudos. Coimbra: GestLegal, 2018 , p. 17.

56 PINTO, Paulo da Mota - Direitos de Personalidade e Direitos Fundamentais - Estudos, pp. 21-25.

57 CARVALHO, Orlando de - Teoria Geral do Direito Civil. 3. ${ }^{\text {a }}$ ed. Coimbra: Coimbra Editora, 2012, p. 106.

58 «(...) o direito geral da personalidade é o seu direito-matriz fundante, aquele em que esses direitos enraízam, pois os «objectos» deles são antes projecções do objecto verdadeiro desta tutela jurídica, que é a personalidade no seu todo», vide, CARVALHO, Orlando de - Teoria Geral do Direito Civil, p. 206. 
Os direitos de personalidade enformam posições jurídicas fundamentais da pessoa pelo simples facto de o ser, são aspetos imediatos de exigência de integração da pessoa, da sua dimensão individual e social dinâmica, revelando emanações do conteúdo essencial da sua personalidade humana agénero, não se tratando já a identidade de género e a não conformidade de género de liberdades inominadas, mas antes de direitos de exigir de outrem o respeito pela própria personalidade.

Com Jorge Miranda, referindo-se aos direitos de personalidade, entendemos que, de igual forma, a identidade e a não conformidade de género «(...) têm por objecto, não algo de exterior ao sujeito, mas modos de ser físicos e morais da pessoa ou bens da personalidade física, moral e jurídica ou manifestações particulares da personalidade humana ou da defesa da própria dignidade» ${ }^{59}$.

O direito à identidade pessoal, integrado no núcleo dos direitos da personalidade, carateriza o ser humano enquanto pessoa individualizada, diferenciando-a de todas as outras, com uma historicidade e vivência pessoal, que são expressão do direito a que cada pessoa viva em concordância consigo mesma. Ora, esta concordância é também expressão do direito à liberdade de consciência que se manifesta nas suas opções e manifestações particulares de vivência.

Compreende-se, assim, a imanente dependência entre o direito à identidade pessoal e o direito à autodeterminação e expressão de género, porquanto aquela será a manifestação exterior de uma vivência interna, eminentemente pessoal. A auto perceção da pessoa sobre si mesma é progressiva e, por isso, dinâmica, impondo-se não só um modelo de tutela diferenciado que acompanhe o desenvolvimento da personalidade humana, mas de igual forma a criação de condições que assegurem materialmente a dimensão legal, social e física do corpo e da identidade de género que dele radica ${ }^{60}$.

O ser humano na sua vivência pessoal, consigo mesmo e com os outros, é infinitamente diversificado, sendo a variabilidade de género uma manifestação desta diversidade. Os estereótipos de género e o estigma associados à não conformidade de género variam de acordo com a padronização de normas sociais e culturais, donde o preconceito e discriminação associados à marginalização também se apresentam em grau diverso, refletindo-se nas pessoas de forma mais ou menos acentuada. Daqui resulta o facto de a disforia de género não ser comum a todos as pessoas que experimentam uma vivência de não conformidade de género.

59 MIRANDA, Jorge - Manual de Direito Constitucional. Tomo IV. Direitos Fundamentais, pp. 66-67.

60 CANOTILHO, J. J. Gomes e MOREIRA, Vital - Constituição da República Portuguesa Anotada - Volume 1. $4 .^{\text {a }}$ Edição. Coimbra: Coimbra Editora, 2007, p. 464. 
A disforia de género consiste no sofrimento ou desconforto sistemático causado pela discordância entre a identidade de género auto percecionada e o papel ou função atribuído socialmente ao sexo atribuído à nascença de acordo com a caraterísticas sexuais primárias e secundárias $^{61}$.

Importa por isso ter presente que a experimentação da discriminação social ${ }^{62}$ é elemento compulsório do desenvolvimento de patologias de saúde mental, nas quais se inclui a disforia de género ou a transfobia internalizada ${ }^{63}$, e não a própria não conformidade de género.

Não se encontram, assim, razões contrárias atendíveis para que a pessoa seja identificada por subsunção a uma categorização binária de sexo anatómico uma vez que seja auto percecionada a não concordância com a sua identidade de género.

O direito ao livre desenvolvimento da personalidade, dimensão daquele direito geral de personalidade e postulado axial de respeito pela dignidade da pessoa humana, implica o reconhecimento de um espaço de liberdade e realização pessoal que convoca a criação de condições efetivas para realização da personalidade ${ }^{64}$.

Justifica-se, neste sentido, que a identidade civil, compreendida na identidade pessoal, postule o reconhecimento jurídico da identidade de género por via da mudança de sexo e nome próprio inscrito no registo civil, sem a antecedência de cirurgia de afirmação de género ${ }^{65}$, porquanto a identidade civil só será expressão da identidade pessoal se com ela coincidir.

61 WORLD Professional Association for Transgender Health - Standarts of Care for the Health of Transsexual, Transgender, and Gender-Nonconforming People, pp. 4-6, 95-97.

62 SCHWEND, Amets Suess - «Trans Health Care from a Despathologization and Human Rights Perspective». In: Public Health Reviews, p. 5.

63 A transfobia internalizada consiste no desconforto pessoal com a auto perceção sobre a não conformidade de género de acordo com as expetativas sociais normativizadas em relação ao género. WORLD Professional Association for Transgender Health - Standarts of Care for the Health of Transsexual, Transgender, and Gender-Nonconforming People, p. 97.

64 «O direito ao desenvolvimento da personalidade recolhe, assim, no seu âmbito normativo de protecção, duas dimensões: (a) formação livre de personalidade, sem planificação ou imposição estatal de modelos de personalidade; (b) protecção da liberdade de acção de acordo com o projecto de vida e a vocação e capacidades próprias e (c) protecção da integridade da pessoa para além do art. $25^{\circ}{ }^{\circ}$, tendo sobretudo em vista a garantia da esfera jurídicopessoal no processo de desenvolvimento». Cf. CANOTILHO, J. J. Gomes e MOREIRA, Vital - Constituição da República Portuguesa... - Volume 1, p. 463.

65 A cirurgia de afirmação de género, também designada de redesignação de género, modifica as caraterísticas sexuais primárias e secundárias, encontrando-se integrada no processo de transição entre o género associado ao sexo morfológico que foi atribuído à nascença para o género com o qual a pessoa se identifica, consistindo num ato médico fundamental para mitigar a disforia de género. O processo de transição é variável e individualizado não incluindo necessariamente a cirurgia de afirmação de género, podendo apenas consistir na feminilização ou masculinização do corpo através de terapias hormonais. WORLD Professional Association for Transgender Health - Standarts of Care for the Health of Transsexual, Transgender, and Gender-Nonconforming People, pp. 95-97; Para efeitos de reconhecimento do direito à identidade pessoal de género cumpre ainda assinalar a jurisprudência do Tribunal Europeu dos Direitos do Homem (TEDH), que no âmbito do processo n. ${ }^{\circ} 13343 / 87$ 
Trata-se, com efeito da passagem da igualdade formal programática para uma igualdade material precetiva, assente numa integração normativa de igualdade constitutiva de uma estrutura social alicerçada na ideia de justiça real.

Não se trata, pois, de imputar ao Direito o acolhimento de uma ideologia de género que visa subverter a natural diferenciação sexual, conforme sustenta Mafalda Miranda Barbosa $^{66}$, porquanto entendemos que é a própria posição ético-axiológica que radica da pessoa humana que convoca a disciplina normativa do Direito e que se impõe pela necessária tutela geral da personalidade no que concerne a direitos humanos fundamentais.

\section{Do princípio da igualdade à critica do paradigma igualitário}

São pilares do sistema de direitos humanos a liberdade, a igualdade e a solidariedade enquanto mecanismos de garantia contra quaisquer formas de discriminação no gozo dos direitos humanos ${ }^{67}$, assumindo o princípio da igualdade a qualidade de princípio jurídico fundamental densificador do próprio conceito de Estado de Direito Democrático e Social ${ }^{68} 69$.

Não se tratando de um instrumento juridicamente vinculativo, a Declaração Universal dos Direitos Humanos (DUDH) não deixa de enunciar e precisar paradigmáticos princípios de respeito pela pessoa e pela sua dignidade, de tal forma que alguns deles elevaram-se a princípios de ius cogens ${ }^{70}{ }^{71}$. É, para todos os efeitos que aqui relevam, o caso do princípio da igualdade.

que opunha uma cidadã transgénero feminina à república francesa decidiu em 1992, pela primeira vez, que a recusa dos Tribunais franceses em autorizarem a alteração do género e nome inscrito no registo civil consistia numa violação do direito sobre a reserva da intimidade da privada, em virtude da disparidade entre o sexo constante daquele registo e o "sexo" vivido pela recorrente, colocando-a frequentemente em circunstâncias humilhantes que provocavam sofrimento psicológico.

66 BARBOSA, Mafalda Miranda e ÁLVAREZ, Tomás Prieto - O Direito ao Livre Desenvolvimento da Personalidade, p. 111. 67 MOREIRA, Vital e GOMES, Carla de Marcelino (Coord.) - «Compreender os Direitos Humanos: Manual de Educação para os Direitos Humanos». [Consult. 28 janeiro 2020]. Disponível em http://pfdc.pgr.mpf.mp.br/atuacaoe-conteudos-de-apoio/publicacoes/direitos-humanos/livro-compreender-os-direitos-humanos, p. 44.

68 CANOTILHO, J. J. Gomes e MOREIRA, Vital - Constituição da República Portuguesa ... - Volume 1. pp. 336-337.

69 «Não existe ordenamento jurídico (ao menos no mundo civilizado) que não proclame fundamentar-se no princípio da igualdade, enquanto núcleo densificador da própria ideia de justiça e de Direito. Por conseguinte, todos os seres humanos são, ao menos teoricamente, iguais.». Cf. RAPOSO, Vera Lúcia Carapeto - «Paridade, a Outra Igualdade». In: Ciências Jurídicas Civilísticas: Comunitárias; Económicas..., pp. 571-572; «Porque todos têm a mesma dignidade social (outra maneira de referir a dignidade da pessoa humana, base da República), a lei tem de ser igual para todos.», vide, MIRANDA, Jorge e MEDEIROS, Rui - Constituição Portuguesa Anotada. Tomo I. Coimbra: Coimbra Editora, 2008, p. 120.

70 MIRANDA, Jorge - Curso de Direito Internacional Público. 4. ${ }^{\text {a }}$ ed. Lisboa: Principia, 2009, pp. 126, 297-299.

71 Não obstante as regras jurídicas, por via de regra, apresentarem as caraterísticas enunciadas ao Direito Cogente de imperatividade e vinculatividade, a expressão latina pretende evidenciar que se trata de regras que estão para além da vontade ou do acordo de vontades dos sujeitos de Direito Internacional, revestindo-se de uma força jurídica imanente ao primado dos direitos das pessoas. MIRANDA, Jorge - Curso de Direito Internacional Público, pp. 119-120. 
O conceito de igualdade, enquanto princípio jurídico, não significa uma igualdade absoluta, não proibindo por isso tratamento diferenciados. Com efeito, se por um lado uma interpretação simplista pode significar a supressão de quaisquer formas de discriminação (situações de desvantagem) ou privilégios (situações de privilégios), uma análise mais atenta evidencia a complexidade do princípio.

Ora, porque existem desigualdades de facto (v.g. físicas), exige-se ao legislador que crie ou recrie oportunidades e condições para que a todos se admita usufruir dos mesmos direitos e, bem assim, cumprir os mesmos deveres. Assim, a igualdade jurídico-material complementa a igualdade jurídico-formal ${ }^{72}$, porquanto é dirigida à igualdade jurídica real ou de resultado.

É, nestes termos, a dimensão social do princípio que convoca a eliminação das desigualdades de facto, impondo-se ao legislador a criação de uma verdadeira igualdade através da lei, conferindo ao princípio sentido positivo ${ }^{73}$.

Por conseguinte, a igualdade, enquanto conceito e princípio jurídico, não opera diacronicamente apenas para proibir discriminações. É também operante na proteção das pessoas contra discriminações resultantes de desigualdades de direito em consequência de desigualdades de facto, concedendo-se liberdade constitutiva ao legislador para corrigir situações que se reputem concretamente iguais ${ }^{74}$.

Com Vera Lúcia Raposo «(...) a igualdade exige também que: a) as situações iguais sejam tratadas de forma igual na medida dessa igualdade; b) as situações diferentes sejam tratadas de modo diferente, na medida dessa diferença (excepto quando tais situações tenham sido artificialmente criadas pelo legislador, porquanto nesse caso o princípio da igualdade reclama a compensação das desigualdades legislativamente instituída[s]); c) se admitam medidas de discriminação positiva nas situações em que estas sejam instrumento necessário e adequado à colmatação de desigualdades fácticas previamente existentes.> ${ }^{75}$.

O sentido positivo do princípio da igualdade não pode, por isso, considerar-se meramente artificial, dele radicando a obrigação de adoção de medidas de ação afirmativas tendentes a mitigar ou corrigir desigualdades reais que se traduzam em tratamentos ou considerações sociais discriminatórias ${ }^{76}$.

72 MIRANDA, Jorge e MEDEIROS, Rui - Constituição Portuguesa Anotada. Tomo I, p. 120.

73 CANOTILHO, J. J. Gomes e MOREIRA, Vital - Constituição da República Portuguesa Anotada - Volume 1, p. 337.

74 MIRANDA, Jorge e MEDEIROS, Rui - Constituição Portuguesa Anotada. Tomo I, pp. 120, 125-126.

75 RAPOSO, Vera Lúcia Carapeto - «Paridade, a Outra Igualdade». In: Ciências Jurídicas Civilísticas: Comunitárias; Económicas; Empresariais..., p. 572.

76 CANOTILHO, J. J. Gomes e MOREIRA, Vital - Constituição da República Portuguesa Anotada - Tomo I, pp. 337-338. 
A necessidade de adoção de medidas de ação afirmativas resulta assim da consideração da pessoa humana enquanto sujeito de direito, estatuto que no plano normativo, acompanhando de perto Jorge Reis Novais, cumpre um elementar sentido de justiça, com três consequências imediatas: o reconhecimento integral da pessoa como sujeito de direito pressupõe o reconhecimento de autonomia para determinar o seu caminho de vida, sem controlos ou dominações heterónomos; reconhecimento da liberdade de não ser bloqueada na conformação das decisões fundamentais da sua vida; criação de condições materiais para participar com liberdade e igualdade na escolha e deliberação coletivas ${ }^{77}$.

\subsection{A igualdade material enquanto desiderato de recuperação da igualdade formal utópica}

A igualdade formal padece de uma subversiva patologia atento o lacónico e impessoal normativizar geral e abstrato que desconsidera as qualidades específicas dos destinatários, acentuando por esta via a subsistência de desigualdades, que encontram suporte no obsoleto princípio da lei ser igual para todos. «A igualdade formal pressupõe uma disciplina uniforme e interdita regimes personalizados» ${ }^{78}$.

A igualdade material preconiza um regime diferenciado no qual a lei não tem de ser igual para todos, mas antes justa para todos. A presunção de constitucionalidade do regime diferenciador não é arbitrária, porquanto a aleatoriedade num regime diferenciado seria eminentemente discriminatória violando o próprio princípio da igualdade.

Um regime diferenciado radica de um critério juridicamente fundamentado, assumindo as diferenças que o justificam verdadeira relevância jurídica, podendo condicionar o regime jurídico aplicável em matéria de direitos e deveres para grupos determinados de pessoas. «Neste caso, as pessoas serão tratadas equally [e não as equalls], de forma equitativa, inclusive de forma desigual quando tal necessário para repor a verdadeira igualdade, entretanto perdida.» ${ }^{79}$.

77 NOVAIS, Jorge Reis - A Dignidade da Pessoa Humana. Vol. II. Dignidade e Inconstitucionalidade. Coimbra: Almedina, 2016, pp. 106-107.

78 Como bem ressalva Vera Lúcia Raposo a igualdade formal remete à época do liberalismo que atendendo à aparente perfeição da construção daquele brocado, edificou dogmas que encontravam suporte apenas neste período porquanto o valor do ser humano encontrava-se dependente de atributos como a raça, a religião, a cor da pele, o sexo, o título ou o rendimento. Cfr. RAPOSO, Vera Lúcia Carapeto - «Paridade, a Outra Igualdade». In: Ciências Jurídicas Civilísticas: Comunitárias; Económicas; Empresariais..., pp. 573-574; CANOTILHO, J. J. Gomes e MOREIRA, Vital - Constituição da República Portuguesa Anotada - Tomo I, pp. 336-338.

79 RAPOSO, Vera Lúcia Carapeto - «Paridade, a Outra Igualdade». In: Ciências Jurídicas Civilísticas: Comunitárias; Económicas; Empresariais..., p. 574. 
É o conteúdo normativo positivo do princípio que convoca a equidade no tratamento das situações não só como existem, mas como devem existir, alcançando-se através da lei a igualdade e não apenas perante a lei.

Significa isto que a igualdade, enquanto conceito objetivo e fundamentado na lei, aponta para um resultado, enquanto a equidade ${ }^{80}$ será um meio para atingir aquele resultado, justificando-se por força de necessariamente ter de se reconhecer que, mais do que tratar as pessoas de forma igual, é indispensável tratá-las de forma justa ${ }^{81}$.

Ora a igualdade material ou de resultado determina a apreciação material da diferença atendendo à conformação normativa a que fica sujeita e que, naturalmente, tem de se encontrar justificada de acordo com uma análise valorativa não arbitrária.

Acompanhamos por isso Simona Giordano e John Harris na sua conclusão de que «(...) we need to celebrate the differences that obtain between human beings and ensure that, despite these differences, individuals are not disadvantages. We simply should not attempt to eradicate those "inequalities" that are not intrinsically harmful and that many of us regard aa making life more rather than less worthwhile» ${ }^{82}$.

\subsection{Da dialética perdida entre igualdade, desigualdade e diferença}

Na dialética entre os conceitos de igualdade e desigualdade é frequentemente tomada por sinónimo desta última a diferença. São, em bom rigor, antónimos que exprimem significados diferentes.

A desigualdade exprime uma construção hierarquizada e de subordinação, não se tratando de uma mera dissemelhança. A diferença, em sentido oposto, exprime uma não semelhança entre pessoas distintas, que pode fundamentar um tratamento diferenciado legitimo em função de certas particularidades, em relação ao qual não se poderá coordenar uma noção pejorativa, tratando-se a diferença de um reflexo de uma sociedade democrática $^{83}$.

80 «(...) a Equidade é um conceito condicionado por critérios subjetivos e direcionado para uma resposta justa e proporcionada a situações particulares ou a necessidades especiais.». CNECV - Relatório e Parecer sobre a Proposta de Declaração Universal sobre Igualdade de Género. P. 4.

81 «Gender Equity is the process of being fair to men and women. To ensure fairness, measures must often be put in place to compensate for the historical and social disadvantages that prevent women and men from operating on a level playing field. Equity is a means. Equality is the result.». Cfr. UNESCO - Unesco's Gender Mainstreaming Implementation Framework for 2002-2007 - Basic Definitions of Key Concepts and Terms,p. 17.

82 GIRODANO, Simona e HARRIS, John - «What is Gender Equality in Sports?». In: Genetic Technology and Sport: Ethical Questions, p. 213.

83 RAPOSO, Vera Lúcia Carapeto - O Poder de Eva..., pp. 260-261. 
Concretizando, à diferença não equivale a desigualdade. A diferença consiste numa expressão neutra ${ }^{84}$ de não semelhança entre indivíduos, já a desigualdade consiste numa expressão de sociedade hierarquizada negativamente.

Com Teresa Pizzaro Beleza «O que está em causa não é tornar as pessoas iguais (no sentido de semelhantes, isto é, não diferentes) mas desfazer a criação, em boa parte legal, de uma hierarquia entre pessoas.» ${ }^{85}$.

Assim, mais que garantir um tratamento igual independentemente do sexo, hodiernamente, pretende-se assegurar um direito à diferença, em nome do paradigma igualitário, que ultrapasse o caráter negativo que se encontra eminentemente cunhado na polarização dos sexos.

«A igualdade serviu os interesses da justiça enquanto funcionou como arma contra privilégios feudais. A partir do momento em que começou a ser sinónimo de identidade, de rejeição, de diferenciações legítimas, deixou de cumprir a justiça. Uma igualdade que aprisiona, que mutila a verdadeira identidade das pessoas, não é um ideal lícito e justo. A verdadeira liberdade não se compadece com igualizações forçadas. O direito à diferença é condição sine qua non de um direito justo e livre.» ${ }^{86}$.

A obrigação de assegurar o direito à diferença é expressão da dimensão social do princípio da igualdade em resultado material ou real. Enforma assim o dever de, por um lado legislar sempre que se revele necessário acautelar o livre exercício do direito à diferença em todas as suas manifestações, por outro lado legislar sempre que seja necessário combater quaisquer formas de discriminação.

\subsection{Do princípio da igualdade à discriminação positiva: um caminho percorrido pelo direito anti discriminatório}

\subsubsection{O princípio da igualdade e o princípio da não discriminação}

Com Teresa Pizarro Beleza, pode-se afirmar que «Os fenómenos sociais de discriminação têm uma dupla face: por um lado, consistem em práticas de domínio e rejeição de pessoas com base (com pretexto) em certas caraterísticas. Por outro, essas práticas são acompanhadas e fundadas em construções de identidade(s) baseadas nessas características pretensamente (vistas como) diferenciadoras. Ambos os processos se alimentam mutuamente, alicerçando-se no senso comum que por sua vez os reconstrói continuamente.» ${ }^{87}$.

84 Portanto sem conotação positiva ou negativa.

85 BELEZA, Teresa Pizarro - Direito das Mulheres e da Igualdade Social..., p. 88.

86 RAPOSO, Vera Lúcia Carapeto - O Poder de Eva..., p. 262.

87 BELEZA, Teresa Pizarro - Direito das Mulheres e da Igualdade Social..., p. 96. 
Trata-se hodiernamente da representação da mitologia grega do titã Prometeu que amarrado eternamente a uma rocha via o seu fígado, que se regenerava todos os dias, ser comido por uma águia.

A discriminação consiste, assim, numa prática social reiterada com conotação pejorativa, encontrando-se associada a preconceitos, intolerância ou favoritismos, consubstanciando uma diferenciação negativa, uma expressão de sentido negativo, não deixando, contudo, de ser um conceito dinâmico ${ }^{88}$.

O princípio da igualdade é, nestes termos, orientador de um duplo conteúdo que se pode assacar ao conceito de discriminação. «Poder-se-á distinguir entre um conceito amplo de discriminação, enquanto toda a infracção ao princípio da igualdade, e um conceito mais restrito, emergente quando a igualdade seja violada com base em fundamentos expressamente proibidos nos textos constitucionais (...).» ${ }^{89}$.

Assim, o artigo $13 .{ }^{\circ}$ da Constituição da República Portuguesa (CRP) proíbe o tratamento desigual entre pessoas, enunciando fundamentos ilegítimos de distinção (v.g. ascendência, sexo, raça, língua, território de origem, religião, convicções políticas ou ideológicas, instrução, situação económica, condição social ou orientação sexual $)^{90}$.

Parece, todavia, que duas consequências imediatas poder-se-ão assacar: a primeira, de que a criação e desconstrução de categorias discriminatórias não podem colocar-se à parte da reflexão à luz de outras ciências sociais; a segunda, de que à própria ciência jurídica compete dar o seu contributo para a desconstrução daquelas, partindo do pressuposto que participa na edificação destas atenta a dimensão jurídica da estrutura social que aqui releva.

A discriminação encontra a sua matriz conceptual na distinção operada pela perceção diferenciada em relação a categorias específicas, podendo verificar-se sob a forma de restrição, exclusão ou preferência fundada em certas características da pessoa (v.g. género, raça, idade, orientação sexual, confissão religiosa) ${ }^{91}$, sempre que a finalidade ou efeito se subsuma à «(...) destruição ou comprometimento do reconhecimento, gozo ou exercício dos direitos humanos e das liberdades fundamentais em condições de igualdade» ${ }^{92}$.

A proibição de discriminação radica assim daquilo que se tem entendido consistir em situações de desigualdade qualificada (cujo elenco meramente enunciativo se encontra no n..$^{\circ}$ do art. ${ }^{\circ} 13 .{ }^{\circ}$ da CRP), proibindo qualquer forma de tratamento diferenciado ilegítimo,

88 RAPOSO, Vera Lúcia Carapeto - O Poder de Eva..., p. 297.

89 RAPOSO, Vera Lúcia Carapeto - O Poder de Eva..., p. 298.

90 BELEZA, Teresa Pizarro - Direito das Mulheres e da Igualdade Social...., p. 103.

91 BELEZA, Teresa Pizarro - Direito das Mulheres e da Igualdade Social..., p. 102.

92 RAPOSO, Vera Lúcia Carapeto - «Paridade, a Outra Igualdade». In: Ciências Jurídicas Civilisticas: Comunitárias; Económicas; Empresariais..., pp. 576-577. 
cujo referencial fundamental se encontra intrinsecamente ligado à dignidade da pessoa humana, que não se compadece com o desfavorecimento da pessoa por força da sua pertença a determinados grupos com caraterísticas particulares ${ }^{93}$.

A ilegitimidade e a inconstitucionalidade das práticas discriminatórias encontram-se, por isso, proibidas pela norma constitucional, mas não já a diferenciação, cuja expressão jurídica pode resultar de uma imposição de justiça no caso concreto.

Todavia, não se poderá compreender esta norma apenas enquanto comando proibitivo de discriminações. Em bom rigor, da norma constitucional também se alcança um uma dimensão protetora ${ }^{94}$ da integridade da pessoa humana contra quaisquer discriminações.

A obrigação de diferenciação reveste-se, nestes termos, de um conteúdo subjetivo de proteção, consistindo num vetor do princípio da igualdade que adstringe o legislador à compensação de situações de desigualdade, permitindo ou impondo, diferenciações que sejam materialmente justificadas e legítimas à luz de critérios de justiça, proporcionalidade, solidariedade e segurança jurídica ${ }^{95}$.

A proibição de arbítrio consiste num controlo negativo, exprimindo um repúdio por tratamentos diferenciados que não encontrem fundamento em valores objetivos e constitucionalmente relevantes, condenando em simultâneo o tratamento diferenciado de situações iguais ${ }^{96}$.

O princípio da igualdade compreende, assim, um limite material interno quanto à discricionariedade em relação aos fundamentos legítimos da diferenciação e que subjazem ao direito anti discriminatório.

O direito anti discriminatório surge, por conseguinte, para mitigar as insuficiências do princípio da igualdade, dirigindo-se a um resultado material que ultrapasse políticas ou procedimentos aparentemente neutros, mas cujos efeitos revelem uma categorização de pessoas consistente em discriminações ilícitas ou ilegítimas.

Por conseguinte, na prossecução da finalidade do direito anti discriminatório, o critério diferenciador - porquanto não se poderá deixar de considerar que, regra geral, a norma não compreende no texto uma diferenciação constitucionalmente permitida - será o da produção do resultado que afete um determinado grupo de pessoas e não na referência expressa ao critério diferenciador ${ }^{97}$.

93 O princípio da não discriminação é um dos vetores do princípio da igualdade, atentas as suas três dimensões fundamentais: a proibição de arbítrio e de discriminação e a obrigação de diferenciação. RAPOSO, Vera Lúcia Carapeto - O Poder de Eva..., pp. 263-264.

94 MIRANDA, Jorge e MEDEIROS, Rui - Constituição Portuguesa Anotada. Tomo I, p. 121.

95 RAPOSO, Vera Lúcia Carapeto - O Poder de Eva..., pp. 263-264.

96 RAPOSO, Vera Lúcia Carapeto - O Poder de Eva..., p. 263.

97 RAPOSO, Vera Lúcia Carapeto - O Poder de Eva..., p. 301. 
Expressão do direito anti discriminatório é a discriminação positiva que se destina precisamente ao combate a regimes discriminatórios radicados do próprio plano jurídico-normativo ${ }^{98}$.

Aproximando-nos do conceito de discriminação positiva, com Jorge Miranda e Rui Medeiros, subsumem-se «(...) a situações de vantagem fundadas, desigualdades de direito em resultado de desigualdades de facto e tendentes à superação destas e, por isso, em geral, de carácter temporário.» ${ }^{99}$.

Uma aparente contradição nos termos: "discriminação" expressa, comummente, um sentido negativo de tratamento diferenciado, enquanto "positiva" expressa precisamente o oposto do termo que adjetiva.

Cremos, por isso, que a expressão deverá ficar reservada a situações muito bem delimitadas e justificadas à luz da CRP, porquanto o desiderato da igualdade jurídica de direitos e oportunidades deverá ser presidido pelo critério de proibição de qualquer forma de discriminação. Não obstante, e atendendo a que a expressão "discriminação positiva" é tradicional no ordenamento jurídico português, é esta a empregue neste no texto.

\subsubsection{A discriminação positiva}

A discriminação pode apresentar-se segundo três modelos: discriminação direta, discriminação indireta e discriminação positiva.

Considera-se discriminação direta ${ }^{100}$ todas as situações em que, designadamente, em função do sexo, as pessoas se encontram sujeitas a um tratamento menos favorável do que aquele que é, tenha sido, ou possa vir a ser dado a uma pessoa em situação comparável ${ }^{101}$. Entende-se por discriminação indireta a situação de desfavor decorrente de uma disposição, critério ou prática aparentemente neutros, mas que determinam um resultado particularmente desfavorável a um grupo determinado de pessoas ${ }^{102}$.

Distinguem-se na exata medida em que na primeira a norma cria diferenciações assentes em critérios proibidos, enquanto na segunda a norma cria requisitos, impedimentos ou proibições que, pese embora se apresentem aplicáveis a todos, determinam a emergência

98 RAPOSO, Vera Lúcia Carapeto - «Paridade, a Outra Igualdade». In: Ciências Jurídicas Civilísticas: Comunitárias; Económicas; Empresariais...., pp. 575-576.

99 MIRANDA, Jorge eMEDEIROS, Rui - Constituição Portuguesa Anotada. Tomo I, p. 120.

100 MIRANDA, Jorge e MEDEIROS, Rui - Constituição Portuguesa Anotada. Tomo I, p. 120.

101 Alínea a) do art. $^{\circ} 3 .^{\circ}$ da Lei N. ${ }^{\circ} 14 / 2008$, de 12 de março, que proíbe e sanciona a discriminação em função do sexo no acesso a bens e serviços e que transpõe a Diretiva N. ${ }^{\circ}$ 2004/113/CE para o ordenamento jurídico interno.

102 Alínea b) do art. $^{\circ} 3 .^{\circ}$ da Lei N. ${ }^{\circ}$ 14/2008, de 12 de março, que proíbe e sanciona a discriminação em função do sexo no acesso a bens e serviços e que transpõe a Diretiva N. ${ }^{\circ}$ 2004/113/CE para o ordenamento jurídico interno. 
de grupos que, à partida, encontrar-se-ão excluídos de cumprir as exigências, ultrapassar os obstáculos ou evitar as proibições ${ }^{103}$.

A discriminação positiva, contrariamente à negativa (à qual seriam subsumíveis tanto a discriminação direta como a indireta), é um instrumento de combate aos regimes discriminatórios, radicando na valoração que deve ser endereçada a determinadas caraterísticas pessoais ${ }^{104}$, sem que daqui resulte um tratamento preferencial ou mais vantajoso.

Com efeito, a discriminação positiva visa combater a discriminação tour court, designadamente, através de medidas transitórias que visam compensar lacunas que, de alguma forma, se revelam atentatórias da dignidade de destinatários de grupos específicos ${ }^{105}$.

Em bom rigor, funciona como impulso de uma verdadeira igualdade substantiva, criando oportunidades iguais para grupos específicos que reclamam uma tutela diferenciada do ordenamento jurídico.

Trata-se de medidas em que «O benefício que aportam para o colectivo não lesa terceiros de forma direta e imediata, mantendo-se nos limites ditados pelo princípio da igualdade em sentido material, mas superando, com o seu carácter radical, a igualdade em sentido formal.» ${ }^{106}$, partindo de disposições, critérios ou práticas objetivamente justificáveis à luz da legitimidade do fim prosseguido e assentes em meios adequados, necessários e proporcionais para atingir aquele fim.

As medidas de discriminação positiva operam, assim, com recurso a regimes diferenciados, mas não discriminadores, porquanto visam satisfazer o princípio da igualdade em sentido material, que convoca, em situações particulares, tratamentos desiguais (à partida) enquanto via de alcançar a igualdade como resultado (à chegada) ${ }^{107}$.

A este propósito esclarece Vera Lúcia Raposo que «Fala-se em igualdade de oportunidades para exprimir aquela primeira e em igualdade de resultados para expressar esta segunda. A realização da igualdade à chegada apenas pela discriminação positiva pode ser

103 RAPOSO, Vera Lúcia Carapeto - O Poder de Eva..., p. 301.

104 RAPOSO, Vera Lúcia Carapeto - «Paridade, a Outra Igualdade». In: Ciências Jurídicas Civilísticas: Comunitárias; Económicas; Empresariais..., pp. 575-576.

105 RAPOSO, Vera Lúcia Carapeto - O Poder de Eva..., pp. 304-312; RAPOSO, Vera Lúcia Carapeto - «Quotas de Género: os prós e os contras de uma solução polémica». In: Direitos Humanos das Mulheres. Coimbra: Coimbra Editora, 2005, p. 112; RAPOSO, Vera Lúcia Carapeto - «Paridade, a Outra Igualdade». In: Ciências Jurídicas Civilisticas: Comunitárias; Económicas; Empresariais..., p. 579.

106 RAPOSO, Vera Lúcia Carapeto - «Paridade, a Outra Igualdade». In: Ciências Jurídicas Civilísticas: Comunitárias Económicas; Empresariais..., p. 579.

107 RAPOSO, Vera Lúcia Carapeto - O Poder de Eva..., pp. 313-320; RAPOSO, Vera Lúcia Carapeto - «Quotas de Género: os prós e os contras de uma solução polémica». In: Direitos Humanos das Mulheres, p. 112; RAPOSO, Vera Lúcia Carapeto - «Paridade, a Outra Igualdade». In: Ciências Jurídicas Civilísticas: Comunitárias; Económicas; Empresariais..., p. 579. 
garantida. As restantes medidas de igualdade são insuficientes para a realizar, ficando-se, mais modestamente, pela igualdade à partida.»108.

Ora, a discriminação positiva tem caráter transitório/temporário, subsistindo enquanto se verifiquem os handicaps de grupos específicos. São, neste sentido, medidas de promoção destinadas a grupos específicos que apresentam determinadas caraterísticas particulares e que em função destas encontram obstáculos à sua livre e autónoma evolução social (v.g. deficientes) ${ }^{109}$.

Daqui resulta o paradoxo do emprego de medidas de discriminação positiva no que respeita ao género. Os seres humanos, de acordo com a categorização binária, não enformam um grupo ou categoria, representam sim a humanidade, seja numa dimensão quantitativa seja numa dimensão qualitativa ${ }^{110}$.

Facto que é transversal à humanidade, e ao qual ninguém se pode furtar, é o de ser integrada por seres humanos. Ora, a caraterística do genoma humano ${ }^{111}$, enquanto elemento que nos conduz à pertença da espécie humana, não constitui per se um handicap que justifique medidas de discriminação positiva atento o caráter transitório e temporário destas. A existirem, seriam sim perpétuas, o que contrariava a natureza intrínseca destas medidas.

Com efeito, não é legitima qualquer sexualização do princípio da igualdade da qual se infira uma correspondente sexualização dos direitos, porquanto os direitos reconhecidos à pessoa humana não conhecem género, não distinguem o género humano.

Um verdadeiro Estado de Direito Democrático Social, no contexto de uma sociedade plural, não é reflexo de uma sociedade padronizada, homogénea, uniforme, é antes expressão de uma sociedade heterogénea que se compromete com a promoção do gozo e do exercício dos direitos a todos os indivíduos, que reclamam medidas não artificializadas de promoção de uma igualdade efetiva e que sejam expressão do reconhecimento de um verdadeiro direito à diferença.

108 RAPOSO, Vera Lúcia Carapeto - «Paridade, a Outra Igualdade». In: Ciências Jurídicas Civilísticas: Comunitárias; Económicas; Empresariais..., pp. 579-580.

109 RAPOSO, Vera Lúcia Carapeto - «Paridade, a Outra Igualdade». In: Ciências Jurídicas Civilísticas: Comunitárias; Económicas; Empresariais..., p. 584

110 RAPOSO, Vera Lúcia Carapeto - «Paridade, a Outra Igualdade». In: Ciências Jurídicas Civilísticas: Comunitárias; Económicas; Empresariais...., p. 584.

111 Por genoma entende-se «a totalidade do material genético presente em cada organismo. (...) Todos os seres humanos têm um genoma idêntico, contudo, entre cada um de nós, existem variações fisiológicas e patológicas que tornam o genoma individual único». Cf. SANTOS, Heloísa G. e PEREIRA, André Dias - Genética para Todos. De Mendel à Revolução Genómicas do Século XXI: a prática, a ética, as leis e a sociedade. Lisboa: Gradiva, 2019, pp. 18-20. 


\subsection{De cisgénero para transgénero: paridade, a nova igualdade agénero}

Pense-se na paridade enquanto nova forma de igualdade. Na verdade, a igualdade material surge como formar de corrigir as lacunas apresentadas pela igualdade formal, apresentando-se a paridade como a teoria aplicada pura da igualdade ${ }^{112}$.

A paridade, por oposto às quotas, não tem como objetivo a compensação provisória de desigualdades, mas antes a definição perpétua de uma representação igualitária.

A paridade consiste num fim em si mesma e não um instrumento para um fim, porquanto é a própria paridade que perfaz a igualdade, ao contrário das quotas são um instrumento para a realizar a igualdade.

Neste sentido, a paridade apresenta-se como um fim que concretiza um resultado material ou real de igualdade, por via de uma abordagem diferenciada à diferença, congregando em si mesma o reconhecimento de que a humanidade é infinitamente diversa nas suas caraterísticas, heterogeneidade que se há de aferir por referencial a todas as pessoas que a integram.

Impõe-se, assim, uma reconfiguração ou adequação do conteúdo substantivo da paridade. Por conseguinte, partindo-se do pressuposto de que inicialmente «A paridade existe na medida em que se defenda que a diferença sexual é a mais decisiva classificação da espécie humana. Ou seja, cada um é aquilo que é em função do respectivo sexo, sendo também este a demarcar a porção a que cada um tem direito no leque de bens disponíveis,

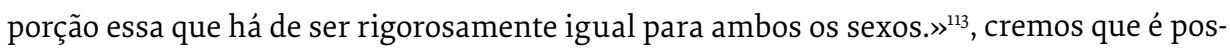
sível avançar paulatinamente para um equilíbrio sinalagmático entre as diferenças das pessoas e as caraterísticas que lhe são comuns, alcançando-se a definiç̧ão permanente de uma igualdade material.

Acompanhando Teresa Pizarro Beleza «No processo de negociação permanente que é a criação da nossa identidade, a nossa auto-identificação como, por exemplo, homens ou mulheres está inevitavelmente condicionada pela nossa interiorização ou rejeição crítica das expectativas sociais, morais, jurídicas quanto ao nosso comportamento (... $)^{114}$, pelo que importa ter presente que um aspeto fundamental da dimensão subjetiva do princípio da dignidade da pessoa humana é a sua integridade que, não só mas também, se desenvolve por referência à proibição de alienação identitária como garantia de controlo sobre a identidade, da sua vivência pessoal e da sua apresentação em público ${ }^{115}$.

112 RAPOSO, Vera Lúcia Carapeto - «Paridade, a Outra Igualdade». In: Ciências Jurídicas Civilísticas: Comunitárias; Económicas; Empresariais..., p. 587.

113 RAPOSO, Vera Lúcia Carapeto - «Paridade, a Outra Igualdade». In: Ciências Jurídicas Civilísticas: Comunitárias; Económicas; Empresariais..., p. 588.

114 BELEZA, Teresa Pizarro - Direito das Mulheres e da Igualdade Social..., p. 71.

115 NOVAIS, Jorge Reis - A Dignidade da Pessoa Humana. Volume II..., p. 107. 
Em relação de assimilação recíproca com princípio da dignidade da pessoa humana e o livre desenvolvimento da personalidade, encontramos as garantias de expressão, desenvolvimento e proteção da pessoa enquanto pessoa concreta, que daqueles princípios radicam. Tais garantias são os direitos de fundamentais de personalidade, que se fundam na própria existência do indivíduo, consistindo por isso na mais direta concretização material de exigência de conformação e observância da dignidade da pessoa humana ${ }^{116}$.

Sendo certo que o direito à identidade pessoal de género pertence ao núcleo essencial das garantias de expressão da pessoa enquanto pessoa, a proibição de alienação identitária impõe a adoção de medidas materialmente afirmativas de apresentação do ser da pessoa interno e externo, que não se podem reduzir apenas à identidade civil.

Resulta assim que a dimensão individual do ser na sua relação com a sociedade convoca uma jusfundamentalização de direitos específicos que possibilitem o desenvolvimento da sua personalidade e identidade, que reputem uma harmonização entre a sua verdade pessoal e a sua apresentação pública, enquanto forma de observância da dignidade da pessoa humana.

Em bom rigor é consensual que a igual dignidade que a ordem jurídica reconhece a cada pessoa é reiteradamente desrespeitada na sua igual condição humana por via da estigmatização endereçada a quem se afasta da padronização socialmente construída leia-se que o mesmo é aplicável às caraterísticas pessoais endógenas - limitando a autodeterminação pessoal do indivíduo nas diversas manifestações externas da sua vivência internalizada.

Com Jorge Reis Novais entende-se que toda a pessoa tem «(...) direito a ser tratada como um igual (as equal), o direito a beneficiar de uma igual consideração e respeito por parte do Estado e da comunidade política (equal concern), ou, como defende Singer, o direito a uma igual consideração dos interesses de cada um» ${ }^{117}$.

Por conseguinte a paridade enquanto fim para a verdadeira igualdade material ou de resultado assume particular relevância no desporto porquanto permite e legitima a definição permanente de um modelo de participação nas competições desportivas individuais que encontra a sua matriz fundante nas diferenças das pessoas e as caraterísticas que lhe são comuns.

Esta igualdade material ou se resultado, alcança-se por via de uma equiponderação que permitirá obstar a distinções desqualificantes reiteradas que consubstanciam uma recusa

116 Mecanismos operativos dos direitos fundamentais e que protegem bens jurídicos da personalidade tais como a vida, a integridade física e psíquica, a liberdade geral de ação e a privacidade. NOVAIS, Jorge Reis - A Dignidade da Pessoa Humana. Volume IDignidade e Direitos Fundamentais. 2. ${ }^{a}$ edição. Coimbra: Almedina, 2018, ..., p. 193.

117 NOVAIS, Jorge Reis - A Dignidade da Pessoa Humana. Volume II..., p. 133. 
prática de igual dignidade, cumprindo a observância e conformação com o paradigma que deve presidir a quaisquer regulamentações normativas, ou seja, o respeito pela humanidade intrínseca, que se justifica pela inadmissibilidade de uma «(...) discriminação desqualificante (...) em função do ser, da natureza da pessoa ou da presença de características independentes da sua vontade e da responsabilidade do próprio (...) $>^{118}$, como o género ou sexo anatómico.

No desporto de competição a discriminação de atletas transgénero e diferenças no desenvolvimento sexual não se traduz apenas na desqualificação. Em bom rigor, a discriminação é estigmatizante e violadora do primado da pessoa humana, entrando em conflito com a sua autodeterminação pessoal, que foi subjetivada em direito para que justamente se assegure à pessoa humana a manifestação externa do poder de autodeterminação que é.

Não se trata de uma mera violação ao princípio da igualdade. Trata-se, sim, de uma violação qualificada em função do sexo por via da estigmatização assente num preconceito socialmente edificado, dirigido a destinatários específicos em função da sua vivência pessoal e de caraterísticas particulares que encontra respaldo num argumento, ainda por consolidar cientificamente, de vantagem biológica em relação a atletas cisgénero.

Fica assim, de resto, por esclarecer a partir de que momento é que as caraterísticas genéticas, biológicas e físicas naturais passaram a ser injustas e assim subsumíveis ao argumento da justiça como ponto de partida no desporto.

\section{Atletas transgénero e com diferenças no desenvolvimento sexual: a do direito à identidade pessoal de género controvérsia da lotaria genética natural}

\subsection{Crónicas de discriminação (in)direta no desporto pela representação e reprodução sexuada da justiça}

Se do ponto de vista do quadro de proteção internacional ou interno de direitos humanos é possível afirmar que os direitos das pessoas transgénero se encontram formalmente tutelados, quanto aos resultados materiais da eficácia destes instrumentos não se pode afirmar o equivalente.

Um dos setores com maior incidência de impedimentos de participação de atletas transgénero femininas ou com diferenças de desenvolvimento sexual é precisamente o do desporto individual de competição ${ }^{119}$, em resultado da maioria dos eventos realizados se

118 NOVAIS, Jorge Reis - A Dignidade da Pessoa Humana. Volume II..., p. 134.

119 Neste conteúdo cumpre assinalar que o objeto em relação ao qual se desenvolve o texto é o da participação de atletas em competições individuais e não em grupo que, por razões relativas à delimitação do objeto do texto, não são aqui tidas em consideração. 
organizarem de acordo com a categorização binária de sexo (não obstante a consideração de outros fatores como a idade e peso).

A premissa fundamental é, nestes termos, que o género é uma caraterística da humanidade e que a humanidade é sexuada de acordo com o modelo binário.

Coloca-se, assim, um obstáculo às atletas que pretendam participar de acordo com a identidade de género auto percecionada ou de acordo com caraterísticas endógenas imanentes.

Com maior ou menor destaque na comunicação social alguns casos controversos quanto à participação de atletas transgénero femininas ou DDS foram discutidos em instâncias jurisdicionais desportivas e órgãos responsáveis pelo sistema desportivo no estrangeiro, pelo que enunciamos abreviadamente alguns dos mais paradigmáticos.

Em 1976 foi solicitado um teste de determinação de sexo biológico a Renee Richards, uma atleta transgénero feminina que se encontrava endereçada a participar na categoria feminina da modalidade. $O$ teste foi recusado e a atleta foi afastada da competição ${ }^{120}$. Nesta sequência o caso foi levado ao United States Supreme Court que reconheceu que a exigência de realização de um teste para determinação do sexo biológico consistia numa ingerência discriminatória e não justificada na privacidade e sobre o próprio corpo e sexualidade da atleta $^{121}$. A atleta foi assim admitida a participar no US Open, sendo que vinte e cinco atletas cisgénero femininas retiraram-se de um futuro torneio argumentando que «(...) Dr. Richards's presence was unfair, that despite her operation and resulting feminine appearance, she still retained the muscular advantages of a male and genetically remained a male» ${ }^{122}$.

Dutee Chand, atleta hiperandrogénica ${ }^{123}$ indiana de sprint, após ganhar a medalha de ouro em 200 e 400 metros respetivamente em 2014, viu a sua participação na Asian Junior Athletics ser alvo de escrutínio devido ao seu elevado nível de testosterona. Com o objetivo de determinar o seu género biológico foi sujeita a testes de sangue, análises aos cromossomas, um MRI ${ }^{124}$ e um exame ginecológico. Na sequência destes foi banida das competições

120 SCHULTZ, Jamie - «Caster Semenya and the "Question of Too": Sex Testing in Elite Women's Sport and the Issue of Advantage». In: Quest, p. 235.

121 BIANCHI, Andria - «Transgender Women in Sports». In: Journal of the Philosophy of Sport, p. 232; SCHULTZ, Jamie - «Caster Semenya and the "Question of Too": Sex Testing in Elite Women's Sport and the Issue of Advantage». In: Quest, p. 235.

122 SCHULTZ, Jamie - «Caster Semenya and the "Question of Too": Sex Testing in Elite Women's Sport and the Issue of Advantage». In: Quest, p. 236.

123 O hiperandrogenismo carateriza-se por uma condição endógena consistente numa produção superior de testosterona, assumida regularmente como uma condição médica, que poderá conferir uma vantagem em relação aos restantes atletas.

124 Magnetic resonance imaging. 
na categoria feminina, recebendo concomitantemente a advertência de que deveria medicar-se com supressores hormonais ou submeter-se a uma cirurgia de forma que os níveis de testosterona fossem reduzidos ou, pelo menos, atenuados ${ }^{125}$.

Em 2015, a atleta recorreu ao Court of Arbitration for Sport (CAS) invocando a invalidade dos regulamentos da International Association of Atheletics Federation (IAAF) relativos ao hiperandrogenismo com as seguintes motivações: tratarem-se de regulações discriminatórias em função de caraterísticas naturais e em função do sexo; inexistência de fundamentos científicos relativamente ao critério fundado nos níveis de testosterona; e, violação do princípio da proporcionalidade na distinção entre atletas femininos e masculinos ${ }^{126}$.

O CAS suspendeu a aplicação dos regulamentos da federação internacional relativos ao hiperandrogenismo por dois anos, determinando que neste prazo fossem apresentadas evidências científicas que demonstrassem a relação entre o nível de testosterona e a vantagem na performance dos/as atletas ${ }^{127}$.

Não tendo apresentado evidências científicas que comprovassem a vantagem que fundava a discriminação que desqualificava a atleta até à verificação do prazo, a IAAF aprovou, contudo, nova regulamentação a 23 de abril de 2018 que estabelece as condições de elegibilidade de atletas com diferenças no desenvolvimento sexual, ainda que circunscritas às competições entre os 400 e 1600 metros e eventos equiparados ${ }^{128}$.

Com efeito, e de acordo com o IAAF Explanatory Notes, a vantagem atlética na ordem dos 10 a 12\% dos atletas cisgénero masculinos em relação às atletas cisgénero femininas resulta, entre outros fatores, da largura da estrutura óssea, da superioridade percentual de massa muscular magra e força desta resultante, dos níveis de circulação de hemoglobina, que são potenciados pelo nível de testosterona que intensifica a superioridade no desempenho ${ }^{129}$, o que se deu por comprovado em diversos estudos científicos endocrinológicos que sustentaram a adoção da nova regulamentação ${ }^{130}$.

125 A regulação do hiperandrogenismo pela IAAF foi introduzida em 2011; COOPER, Jonathan - «Testosterone: "the Best Discriminating Factor"». In: Philosophies, p. 2.

126 COURT of Arbitration for Sport - CAS 2014/A/3759, Dutee Chand vs. AFI \& IAAF, p. 10.

127 COURT of Arbitration for Sport - CAS 2014/A/3759, Dutee Chand vs. AFI \& IAAF, pp. 154-156, 158.

128 IAAF - Eligibility Regulations for the Female Classification (Athlets With Differences of Sex Development).

129 IAAF - Elibibility Regulations for the Female Classification (Athletes With Differences of Sex Development) Explanatory Note. P. 1-2; Note-se que na prática esta regulação exclui automaticamente atletas como Caster Semenya.

130 «However, there is also an additional concern raised about how the IAAF has made use of scientific evidence as a basis for justifying the Testosterone Regulations. (...) Bermon and Garnier, may be scientifically flawed, both in terms of what it is capable of showing (only correlation not cause) and in terms of the data resulting in a lack of scientific integrity». Cf. COOPER, Jonathan - «Testosterone: "the Best Discriminating Factor"». In: Philosophies, p. 13. 
A regulação do hiperandrogenismo consiste, assim, numa forma de exclusão de atletas das competições assente em vantagens genéticas decorrentes da produção endógena de testosterona ${ }^{131}$.

O requisito que suscitou maior celeuma foi, com efeito, a regra 2.2. que impõem às atletas a redução dos níveis de testosterona a um valor inferior a 5 nanomols por litro de sangue (nmol/L) de forma permanente enquanto houver pretensões de participar nas competições, designadamente, com o recurso a contracetivos, concomitantemente com o reconhecimento em termos legais da categorização binária feminina, como intersexo ou equivalente ${ }^{132}$.

Em bom rigor, o que resulta desta regulamentação é que lhe está imanente uma conceptualização de patologia do hiperandrogenismo que por isso deve ser objeto de uma intervenção terapêutica de forma que as atletas possam cumprir os requisitos de elegibilidade para competir na categoria feminina com as demais atletas cisgénero. Encontra-se por isso claramente em oposição ao princípio 18 - que reforça a proibição de tratamentos médicos sem o consentimento da pessoa - e ao princípio 32 - que reitera a consolidação do direito à integralidade da pessoa física e psíquica, vertidos na Yogykarta Principles ${ }^{133}$.

Paradigmático é, de igual forma, o caso da atleta Caster Semenya, bicampeã olímpica de 800 metros em atletismo, que tendo suscitado dúvidas quanto à sua elegibilidade para competir na categoria feminina em resultado da sua virilização e aparência ambígua, a solicitação da IAAF foi submetida a testes de verificação de género, bem como aos níveis de testosterona que se revelaram substancialmente elevados em virtude do hiperandrogenismo ${ }^{134}$.

Em 2017 Laurel Hubbard, atleta transgénero feminina da Nova Zelândia da modalidade de levantamento de peso superior a 90 quilogramas na categoria feminina, venceu uma competição internacional, cuja participação foi antecedida pela realização de testes de sangue pelo período consecutivo de doze meses por forma a demonstrar que os seus

131 Note-se que, em circunstâncias competitivas similares, as vantagens genéticas de Usain Bolt nunca foram colocadas em causa. No mesmo sentido, «Whilst dedication and training was, of course, part of Usain Bolt's success, it would be hard to maintain that his recent domination of sprinting was not due, in part, to natural genetic advantages he enjoyed over his competitors. It has been suggested that Bolt, like many other top sprinters, has the "sprinting gene", meaning he may have particulary fast-twitch muscle reflexes and longer fibers than most. Unlike most of sprinters, however, he is $6 \mathrm{ft}$. 5 inches tall. These genetic advantages almost certainly contributed to what makes him especially adept at sprint». Cf. COOPER, Jonathan - «Testosterone: "the Best Discriminating Factor"». In: Philosophies, p. 2.

132 IAAF - Eligibility Regulations for the Female Classification (Athlets With Differences of Sex Development). P. 3.

133 SCHWEND, Amets Suess - «Trans Health Care from a Despathologization and Human Rights Perspective». In: Public Health Reviews, p. 7.

134 SCHULTZ, Jamie - «Caster Semenya and the "Question of Too": Sex Testing in Elite Women's Sport and the Issue of Advantage». In: Quest, pp. 228-233. 
níveis de testosterona não eram superiores aos de quaisquer outras atletas cisgénero que integravam a mesma categoria naquela modalidade ${ }^{135}$ - não obstante, a ideia de que a atleta beneficiava de uma vantagem de ordem biológica permanece ${ }^{136}$.

\subsection{Em busca da discriminação indireta no princípio the skill thesis}

Atenta a igual dignidade de todas as pessoas, sendo proibida qualquer forma direta ou indireta de discriminação, designadamente, por força do exercício do direito à identidade e expressão de género ${ }^{137}$, verifica-se ainda no desporto algumas manifestações de carater discriminatório quanto à participação de atletas transgénero femininas e $\operatorname{DDS}^{138}$ que se antagonizam ao princípio vertido no art. $^{\circ} 5$. $^{\circ}$ da Lei N. ${ }^{\circ} 30 / 2004$, de 21 de julho ${ }^{139}$.

Princípio ético de governança no desporto é o princípio the skill thesis, segundo o qual os resultados das competições desportivas devem ser determinados pela performance dos/ as atletas para os/as quais são dadas as mesmas oportunidades de competir. Em ordem a alcançar este desiderato que remete para uma justiça de resultado é consensual que a utilização de fatores externos que possam ter influência naquele sejam de rejeitar ${ }^{140}$.

Atentemos na organização binária dos/as atletas nas competições desportivas (v.g. ciclismo feminino/masculino, natação feminina/masculina, levantamento de pesos feminino/masculino). A categorização que determina a elegibilidade para cada segmento tem por referencial aos 46 cromossomas organizados em pares, sendo que o 23 cromossoma que determina o sexo identifica a pessoa como mulher na sequência $46 \mathrm{XX}$ e homem na correspondência $46 \mathrm{XY}^{141}$.

135 International Olympic Committee - IOC Consensus Meeting on Sex Reassignment and Hyperandrogenism November 2015.

136 BIANCHI, Andria - «Something Got to Give: Reconsidering the Justification for a Gender Divide in Sport». In: Philosophies, p. 4.

137 Neste sentido o art..$^{\circ}$ 2. $^{\circ}$ da Lei N. $.^{\circ} 38 / 2018$, de 7 de agosto que estabelece o direito à autodeterminação da identidade de género e expressão de género e o direito à proteção das caraterísticas sexuais de cada pessoa.

138 Ter-se-á em consideração tanto atletas DSD como transgénero femininas porque a crítica, designadamente, quanto ao nível de testosterona, é comum. «Although these differences are significant, it is important to consider intersex persons because they are often criticized for having too much testosterone to compete in female categories, which is the thought to give them an unfair advantage. This is the same criticism that is applied to trans*women.» Cfr. BIANCHI, Andria - Transgender Women in Sports. Journal of the Philosophy of Sport. P. 231.

139 Princípio da Não Discriminação - Lei de Bases do Desporto.

140 Os equipamentos utilizados pelos atletas terão assim de ser os mesmos de forma a afastar quaisquer influências exógenas nos resultados, o controlo de doping permite combater a administração de composições promovam uma melhor performance desportiva por via exógena. São, neste sentido, também compreensiveis as críticas apontadas à utilização de próteses de fibra de carbono por Oscar Pistorius nas competições com atletas que não deficientes físicos. Neste sentido, COOPER, Jonathan - «Testosterone: "the Best Discriminating Factor"». In: Philosophies, p. 3.

141 «Whilst dedication and training was, of course, part of Usain Bolt's success, it would be hard to maintain that his recent domination of sprinting was not due, in part, to natural genetic advantages he enjoyed over his 
Duas consequências são imediatamente assacáveis: por um lado, que não se reconhece neste sistema binário a possibilidade de atletas transgénero poderem livremente optar por uma categoria conciliável com a identidade e expressão de género por si auto percebidas ${ }^{142}$ e, por outro lado, que as atletas transgénero femininas não devem competir na respetiva categoria, porquanto encontrar-se-ão numa posição eminentemente vantajosa em virtude de possuírem caraterísticas físicas e fisiológicas, em contraposição com as demais atletas cisgénero, que determinariam uma injustiça como ponto de partida, consequência igualmente observável em relação a atletas com DDS.

A justificação imediata que resulta para a imposição de limites à participação destas atletas é rapidamente apreensível atendendo ao argumento da vantagem física, porquanto os homens cisgénero apresentam uma massa muscular, em média, 30\% superior às mulheres cisgénero, além de regra geral mais altura. A superioridade percentual da massa muscular confere assim mais robustez e potência. Já a elasticidade das fibras musculares das mulheres cisgénero conferem caraterísticas físicas que favorecem os resultados em determinadas modalidades desportivas ${ }^{143}$.

Daqui resulta a tautologia, discriminação generalizadamente tolerada, de não se suscitar celeuma em relação à participação de atletas transsexuais masculinos, atendendo ao pressuposto de que naturalmente se encontram em desvantagem por força das suas caraterísticas físicas e fisiológicas.

É consabido que a terapêutica hormonal de afirmação de género feminino consiste na administração exógena de estrogénio que tem como efeitos clínicos alterações substantivas na composição física e fisiológica que, e para os efeitos que aqui relevam, se traduzem num significativo aumento e redistribuição da gordura corporal, bem como na diminuição acentuada da força e massa muscular ${ }^{144}$. Ora, atendendo a que se trata de uma terapêu-

competitors. It has been suggested that Bolt, like many other top sprinters, has the "sprinting gene", meaning he may have particulary fast-twitch muscle reflexes and longer fibers than most. Unlike most of sprinters, however, he is $6 \mathrm{ft} .5$ inches tall. These genetic advantages almost certainly contributed to what makes him especially adept at sprint». Cf. COOPER, Jonathan - «Testosterone: "the Best Discriminating Factor"». In: Philosophies, pp. 3-4; BIANCHI, Andria - «Transgender Women in Sports». In: Journal of the Philosophy of Sport, p. 232.

142 Naturalmente encontram-se aqui apenas consideradas as atletas que não iniciaram ou não pretendem iniciar a terapêutica hormonal ou recorrer à cirurgia de afirmação de género.

143 IAAF - Elibibility Regulations for the Female Classification (Athletes With Differences of Sex Development) Explanatory Note, p. 2; GLEAVES, John e LEHRBACH, Tim - «Beyond Fairness: The Ethics of Inclusion for Transgender and Intersex Athletes». In: Journal of The Philosophy of Sport, pp. 315-317; MACEDO, Ana - Identidade de Género e Orientação ..., p. 107.

144 As hormonas de estrogénio são as correspondentes ao género com o qual se identifica. A terapia inclui ainda antiadrogénicos que visam suprimir as hormonas que o corpo produz endogenamente por via da inibição dos recetores androgénios, cfr. MACEDO, Ana - Identidade de Género e Orientação ..., p. 86-87; «Anedoctal evidence from the few athletes who discuss their postsurgical and posthormonally transitioned selves assert that their bodies are "greatly weakened" and their testosterone levels are well bellow those of "normal women"». Cf. 
tica ad eternum a clivagem que resultaria em relação às atletas cisgénero encontrar-se-ia mitigada, porquanto a significativa diferença da constituição corporal encontra-se infindavelmente comprometida.

Não se encontrando pacificada a controvérsia nas competições desportivas relativamente à participação de atletas transgénero femininas por esta via, há que assinalar que a testosterona é o argumento que tem perpetuado a discriminação nas competições desportivas, dirigindo-se de igual forma às atletas com diferenças no desenvolvimento sexual.

Com efeito, e atenta a falibilidade dos testes de verificação cromossomática do sexo por força das variações cromossomáticas que determinam que mulheres não sejam necessariamente $46 \mathrm{XX}$ e homens $46 \mathrm{XY}$, reuniram-se os pressupostos para a elevação da testosterona a melhor argumento de discriminação indireta sob o pretenso paradigma de assegurar uma justiça artificial numa área em que precisamente as vantagens físicas e fisiológicas genéticas distinguem os atletas nos resultados.

O argumento da injustiça é regularmente empregue no que concerne à participação de atletas transgénero femininas e DDS enquanto mecanismo de impedimento de participação nas categorias femininas, porquanto se entende que, regra geral, apresentando níveis mais elevados de testosterona ficam imediatamente colocadas numa situação de vantagem do ponto de vista da aptidão física ${ }^{145}$.

Note-se, contudo, de as atletas cisgénero com síndrome de ovários poliquisticos apresentam de igual forma níveis superiores de produção endógena de testosterona em relação à média das restantes atletas, mas quanto a estas o resultado da regulação é tendencialmente inclusivo, por oposição ao resultado de eminente segregação das atletas transgénero femininas e DDS ${ }^{146}$.

Ora, partindo da consideração dos fatores de ordem biológica e genética e atenta a importância da consistência para o desenvolvimento de uma regulamentação adequada a tutelar e garantir a participação das atletas transgénero femininas e com diferenças no desenvolvimento sexual, é necessário adstringir-nos à evidência dos estudos incidentes

SCHULTZ, Jamie - «Caster Semenya and the "Question of Too": Sex Testing in Elite Women's Sport and the Issue of Advantage». In: Quest, p. 235; GLEAVES, John; LEHRBACH, Tim - «Beyond Fairness: The Ethics of Inclusion for Transgender and Intersex Athletes». In: Journal of The Philosophy of Sport, p. 313.

145 «Critics often believe that having, on average, more testosterone gives them an unfair advantage that makes them perform immensely better than their female-born counterparts.». Cfr. BIANCHI, Andria - «Transgender Women in Sports». In: Journal of the Philosophy of Sport, pp. 229-230; Confirmando as vantagens relitivamente a algumas provas na modalidade de atletismo, cfr, IAAF - Elibibility Regulations for the Female Classification (Athletes With Differences of Sex Development) Explanatory Note, p. 6.

146 HIRSCHBERG, Angelica Lindén - «Female Hyperandrogenism and elite sports». In: Endocrine Connections Review, pp. 83, 88-89. 
sobre potenciais vantagens atléticas que aquelas atletas possam apresentar em relação às cisgénero.

$\mathrm{Na}$ verdade, não existe qualquer resultado científico que evidencie que estas atletas beneficiam de alguma vantagem na sua performance em todas as modalidades desporti$\operatorname{vas}^{147}$, sendo certo que ainda há que ponderar o facto de, não obstante, em abstrato o nível de testosterona ser suscetível de se considerar relevante, a aptidão e performance de um/a atleta depende, de igual forma, de um conjunto de fatores externos e internos, tais como a aptidão natural para a modalidade, a sua composição genética, a motivação pessoal, o treino adequado, a alimentação e nutrição, que não podem ser menosprezados.

Em bom rigor, os níveis de testosterona, que têm constituído um verdadeiro impedimento impediente porquanto têm fundado a exclusão de atletas transgénero femininas e com DDS das competições, não garantem por si só que o/a atleta tenha um nível de performance significativamente superior aos restantes atletas em todas as modalidades desportivas.

Não existindo assim razões atendíveis que levem a uma adstrição absoluta aos níveis de testosterona per se, ter-se-á que, concomitantemente, considerar a resposta do corpo do/a atleta ao nível de testosterona para aferir a relevância desta no caso particular ${ }^{148}$.

O termo "testosterona efetiva" remete, precisamente, para o nível de testosterona efetivamente utilizado pelo corpo do/a atleta para incremento da sua aptidão e performance na modalidade desportiva concreta ${ }^{149}$.

Se a resposta concreta do corpo da atleta ao nível de testosterona for relevante, é legítimo afirmar-se que o nível de testosterona enquanto fator determinante de uma performance superior em relação às atletas cisgénero encontra respaldo na justiça de resultado

147 O que se permite inferir, em bom rigor, da regulação da IAAF em relação ao hiperandrogenismo é precisamente que o nível de testosterona é apenas significativo em algumas provas de atletismo, designadamente as provas entre 400 a 1600 metros. Cfr. IAAF - Elibibility Regulations for the Female Classification (Athletes With Differences of Sex Development) Explanatory Note, p. 3-4; O emprego do verbo transitivo "pode" indicia a possibilidade, não a dando por isso por assente. HIRSCHBERG, Angelica Lindén - «Female Hyperandrogenism and elite sports». In: Endocrine Connections Review, pp. 86-89; GLEAVES, John; LEHRBACH, Tim - «Beyond Fairness: The Ethics of Inclusion for Transgender and Intersex Athletes». In: Journal of The Philosophy of Sport, pp. 313-314.

148 SCHULTZ, Jamie - «Caster Semenya and the "Question of Too": Sex Testing in Elite Women's Sport and the Issue of Advantage». In: Quest, pp. 233-234; No mesmo sentido, BIANCHI, Andria - «Transgender Women in Sports». In: Journal of the Philosophy of Sport, p. 233. «According to the fairness argument, transgender women should not be allowed to compete in female categories in sports since they possess unfair advantages due to high levels of testosterone. One explanation for this argument is the skill thesis, which says that sports are meant "to determine which opponent is more skilfull"».

149 SCHULTZ, Jamie - «Caster Semenya and the "Question of Too": Sex Testing in Elite Women's Sport and the Issue of Advantage». In: Quest, pp. 238-239; BIANCHI, Andria - «Transgender Women in Sports». In: Journal of the Philosophy of Sport, p. 233; BIANCHI, Andria - «Something Got to Give: Reconsidering the Justification for a Gender Divide in Sport». In: Philosophies, p. 6. 
que o princípio the skill thesis pretende alcançar, não se traduzindo por isso numa violação ao princípio da igualdade.

Contudo, ter-se-á que ter presente que a lotaria genética natural por si só sempre bastaria para relativizar o princípio the skill thesis porquanto as caraterísticas genéticas sempre serão suscetíveis de determinar uma maior vantagem para alguns atletas quando e se comparados entre si apenas atletas cisgénero ${ }^{150}$.

Tomemos como exemplo a síndrome de Marfan, que consiste numa condição médica que torna a pessoa particularmente alta. Terá esta condição médica relevância ao ponto de excluir um atleta de uma equipa de basketball ou volleyball? Julgamos que não, pese embora a evidência de que quando comparado com outros atletas da mesma modalidade sempre se encontrará em vantagem em relação ao resultado por força da sua altura. Exemplo modelar de caraterísticas genéticas naturais que revelam uma predisposição para alcançar melhores resultados quando comparado com outros atletas cisgénero é também o do atleta é o Michael Phelps ${ }^{151}$.

Em bom rigor, em ambos os exemplos, o que se evidencia é que se tratam de caraterísticas genéticas naturais que não se encontram facilmente nos demais atletas, pelo que se tratam de diferenças que se revestem de potencial para que não se considerem subsumíveis à justiça desportiva radicada da interpretação tradicional do princípio the skill thesis e da qual se alcança a igualdade meramente formal.

Todavia, a elevada percentagem de massa muscular, bem como a inerente força, robustez e agilidade de atletas como Caster Semenya têm suscitado particular atenção por força de uma vantagem genética que determina a diferença em relação a outras atletas cisgénero (níveis endógenos de testosterona) e que por isso tem sido considerada uma vantagem desproporcional e injusta, ao contrário do que sucede com os atletas dados a exemplo, aos quais se associa um sentido positivo de vantagem enquanto "talento natural".

Com efeito, não de poderá deixar de entender que o argumento da testosterona é, na verdade, um pressuposto da organização binária das competições desportivas que resulta

150 Acompanhamos, por isso, Simona Giordano e John Harris na rejeição à proposta de recurso à engenharia genética de melhoramento de Torbjörn Tännjsö e Claudio Tamburrini para alcançar uma verdadeira igualdade de género nas competições desportivas. Cfr. GIRODANO, Simona; HARRIS, John - «What is Gender Equality in Sports?». In: Genetic Technology and Sport: Ethical Questions, pp. 209-216; TÄNNSJÖ, Torbjörn e TAMBURRINI, Claudio (Coord.) - «Gender Equality and Gene Technology in Sport». In: Genetic Technology and Sport: Ethical Questions, pp. 181-195.

151 COOPER, Jonathan - «Testosterone: "the Best Discriminating Factor"». In: Philosophies, p. 2; Para uma análise mais detalhada sobre os testes de verificação de género, cfr, COOPER, Emely J. - «Gender Testing in Athletic Competitions - Human Rights Violations: Why Michael Phelps is Praised and Caster Semenya is Chastised». In: The Journal of Gender, Race \& Justice; e sobre a regulação da vantagem genética, POLEZ, Sarah e LEWIS, anna «Regulating Genetic Advantage». In: Harvard Journal of Law \& Technology. 
da desigual e discriminatória conceptualização em relação às variações genéticas decorrentes do cromossoma sexual e às variações cromossomáticas que determinam outras vantagens físicas, que radicam da edificação socialmente elaborada de hierarquização entre homem e mulher.

Importa por isso ponderar quando é que se torna possível afirmar que determinado desempenho é significativamente superior para que não se possa considerar legítimo numa mulher.

Proposta a ser desconsiderada, pese embora com algumas reservas, é a de Torbjörn Tännsjö e Claudio Tamburrini quanto à eliminação de categorias binárias por referência ao sexo morfológico. Partindo da premissa de que qualquer forma de discriminação sexual é moralmente rejeitável independentemente do contexto e motivações em que se verifique ${ }^{152}$, pretende resgatar o primário desiderato das competições desportivas, segundo o qual os atletas devem competir em igualdade de circunstâncias, sem referência a uma categoria, determinando-se assim por via da performance fáctica e de resultado quem seria o/a melhor atleta.

Não obstante a bondade da proposta, note-se que a categorização binária poderá não consistir numa forma de discriminação sexual injustificada stricto sensu, desde logo por não considerar a possibilidade científica de fatores biológicos (v.g. testosterona) sustentarem a manutenção das categorização binária de género em modalidades específicas, por outro lado não pondera a dimensão social da construção de igualdade de género e do tortuoso caminho que levou à inclusão das mulheres nas competições desportivas que, inicialmente, se encontravam reservadas aos homens ${ }^{153}$.

No âmbito das competições desportivas, o sucesso dos resultados dos/as atletas encontra-se estritamente ligado à maximização das aptidões biológicas naturais. Significa isto que as próprias caraterísticas físicas e fisiológicas que enformam o património genético que é o corpo têm relevância imediata na robustez, resistência, potência e aptidão do/a atleta.

152 TÄNNSJÖ, Torbjörn e TAMBURRINI, Claudio - «The Genetic Design of a New Amazon». In: Genetic Technology and Sport: Ethical Questions, pp. 181 e 185; «For virtually as long as women have been allowed to compete in Athletics (and indeed other sports), there have been rules to segregate competition into male and female categories, a distinction that as historically been made by reference to biological sex. The rational for segregation was, no doubt, initially based on observations, assumptions and generalizations about the athletic ability of men and woman, the perceived "weakness" of the feminine form and cultural stereotypes about the role of women». Cf. COOPER, Jonathan - «Testosterone: "the Best Discriminating Factor"». In: Philosophies, p. 3.

153 SAPPENFIELD, Kourtney - «Adrienne Miller and Jomills Braddock II: Sex Segregation in Sports: Why Separate is Not Equal. In: J Youth Adolescence. California: Praeger, 2016, pp. 2480-2481; GLEAVES, John e LEHRBACH, Tim - «Beyond Fairness: The Ethics of Inclusion for Transgender and Intersex Athletes». In: Journal of The Philosophy of Sport, p. 315 . 
A utopia de justiça que se pretende assacar ao princípio e que sustenta a categorização binária com recurso ao argumento do nível de testosterona, ter-se-á que ter por necessariamente errónea, porquanto a individualidade endógena sempre poderá colocar alguns atletas numa posição eminentemente vantajosa que outros tantos jamais poderão alcançar, concluindo-se pela relativa expressão do princípio em relação ao ponto de partida igualitário na organização binária das competições desportivas ${ }^{154}$.

Resta assim, apreciar duas alternativas: a primeira, que se prescinda do princípio the skill thesis em relação à participação destes/as atletas nas competições ainda que os níveis de testosterona efetiva sejam determinantes no resultado; a segunda, não se prescindindo do princípio, que se atendam às vantagens genéticas de todos os atletas (cisgénero e transgénero e DDS) na organização das competições desportivas, de forma a mitigar as vantagens resultantes da lotaria genética natural ${ }^{155}$.

\section{Conclusão}

Conforme resulta das disposições conjugadas do artigo $1 .^{\circ}$ e do artigo $10 .^{\circ}$ da UNESCO International Charter of Physical Education, Physical Activity and Sports, é princípio fundamental de governança desportiva no acesso à prática desportiva, incluindo as competições profissionais, a não discriminação $0^{156}$.

Este instrumento que necessariamente tem de ser interpretado em conjugação com o quadro legal de proteção internacional de direitos humanos tem, por conseguinte, que se traduzir na criação de condições para o cumprimento integral do desiderato de respeito pela dignidade da pessoa humana, livre desenvolvimento da personalidade, privacidade e integridade.

A organização binária das competições desportivas tem suscitado particular atenção no que concerne à participação das atletas transgénero femininas e com diferenças no desenvolvimento sexual porquanto tem potenciado a violação de um catálogo de direitos imanentes à dimensão ética e ontológica da pessoa humana, que não se compadecem com

154 «I draw on a couple of examples to illustrate this point, such as the case of Michael Phelps, whose genetic attributes provide him with many advantages that is competitors probably lack (e.g. size 14 feet, the fact that he is double jointed, his large 'wingspan')». Cf. BIANCHI, Andria - «Something Got to Give: Reconsidering the Justification for a Gender Divide in Sport». In: Philosophies, p. 6; GLEAVES, John; LEHRBACH, Tim - «Beyond Fairness: The Ethics of Inclusion for Transgender and Intersex Athletes». In: Journal of The Philosophy of Sport, p. 315 .

155 BIANCHI, Andria - «Something Got to Give: Reconsidering the Justification for a Gender Divide in Sport». In: Philosophies, p. 6.

156 UNESCO - International Charter of Physical Education, Physical Activity and Sports. 
a ausência de transparência e consolidação das motivações que presidem à definição de critérios de elegibilidade das atletas.

A justiça de resultado que se pretende alcançar com o princípio the skill thesis é assim meramente formal e não material. A proporcionalidade que se encontra inerente ao argumento da vantagem física destas atletas em comparação com as atletas cisgénero, está longe de justificar as restrições que têm sido colocadas às atletas transgénero femininas e com diferenças no desenvolvimento sexual.

Com efeito, não se poderá aceitar que exista proporcionalidade quando a desvantagem radica apenas de uma potencial redução das possibilidades de ganhar. A proteção conferida pelo complexo de direitos humanos fundamentais torna assim difícil justificar a abstrata vantagem consignada às atletas transgénero femininas e com diferenças no desenvolvimento sexual face ao potencial da lesão dos direitos e liberdades de que estas são também titulares, atendendo ao primado de justiça do resultado material que se prossegue no desporto.

Em bom rigor, trata-se de uma desadequada interpretação do princípio the skill thesis ${ }^{157}$ que tem promovido o impedimento da participação de atletas transgénero femininas e com diferenças de desenvolvimento sexual em diversas competições desportivas ou, não se verificando $a b$ initio o impedimento, suscitado posteriormente decisões que colidem com o direito à autodeterminação de género e ao livre desenvolvimento da personalidade, desde logo porque se refletem no contexto de uma atividade que é central nas suas vidas, mas de igual forma porque faz indiciar o acolhimento da patalogização ${ }^{158}$ das questões relativas ao género.

O princípio não sugere que é a categorização binária e os métodos indiciários que levam à sua subsunção que deverá ser o critério orientador. Na verdade, a meritocracia desportiva não sugere sequer que os/as atletas sejam tratados de forma absolutamente igual, porquanto a diversidade, e consequentemente a diferença, são caraterísticas da espécie humana. O que sugere é que os/as atletas preencham requisitos de elegibilidade para participarem nas competições que tenham por referência as suas caraterísticas biológicas e genéticas naturais que, naturalmente, têm de ser maximizadas, de forma que a competição acolha os/as atletas equally e não as equalls.

157 Este princípio sugere que é a própria prática/execução da modalidade desportiva que deve determinar o/a atleta com maior aptidão, e consequentemente melhores resultados, por via de um ponto de partida justo que coloque os/as atletas em competição numa posição equilibrada entre si.

158 O que resulta aliás bastante evidente na subtil imposição constante das Elibibility Regulations for the Female Classification (Athletes With Differences of Sex Development) da IAAF. 
A verdade desportiva, que decorre do princípio da ética desportiva ${ }^{159}$, tem reforçado a interpretação do princípio the skill thesis quanto à necessidade de atender à aptidão física do atleta no domínio da força, rapidez, agilidade, que pode ser influenciada pelos níveis de testosterona. Ora, a aptidão/habilidade do atleta não pode ser considerada isoladamente, porquanto não se poderá deixar de ter presente que as vantagens genéticas (além da testosterona leia-se) são um facto inarredável no desporto, pelo que a defesa de um ponto de partida equivalente ou justo nas competições sempre consistirá num objetivo utópico.

Encontrando-se as vantagens genéticas dadas por assentes no desporto ${ }^{160}$, não obstante a consagração e projeção prática daquele princípio, e não se pretendendo abdicar deste, terá chegado a altura de ponderar a legitimidade do argumento em relação aos níveis de testosterona para exclusão das atletas transgénero femininas e com diferenças de desenvolvimento sexual.

Tratando-se de caraterísticas genéticas naturais, conforme é o caso do nível de produção de testosterona destas atletas, dificilmente se encontra um critério ético racional para que se atenda particularmente a esta caraterística e outras sejam ignoradas, relativamente a todos/as os/as atletas (cisgénero, transgénero e DDS), justamente numa área em que as vantagens genéticas naturais se encontram em estrita ligação com o resultado e que por isso são maximizadas.

A proposta é, nestes termos, de não abdicar do princípio the skill thesis, mas ponderar a adoção de um modelo de conformidade paritário que, partindo do pressuposto que os resultados desportivos devem basear se na habilidade física das atletas, progrida para a eliminação de categorias por referência ao género binário ${ }^{161}$, cumprindo-se por um lado o conteúdo substantivo do princípio da não discriminação e por outro lado promovendo a inclusão de todos os/as atletas numa competição que cumpra o desiderato igualitário de justiça material.

Com efeito, reconhecendo-se as profícuas finalidades do princípio the skill thesis, é a equidade do resultado da aplicação prática do princípio que conduz à necessidade de mitigar potenciais vantagens por um critério de justiça nas competições desportivas.

159 Particularmente n. ${ }^{\circ} 1$ e 2 do art. $^{\circ} 3 .^{\circ}$ da Lei N. ${ }^{\circ}$ 5/2007, de 16 de janeiro, que define as bases das políticas de desenvolvimento da atividade física e desportiva, bem como o n. ${ }^{\circ} 1$ e 2 do art. $^{\circ} 40 .^{\circ}$ da Lei N. ${ }^{\circ} 30 / 2044$, de 21 de julho, que define as bases gerais do sistema desportivo.

160 IAAF - Elibibility Regulations for the Female Classification (Athletes With Differences of Sex Development) Explanatory Note. P. 6.

161 No mesmo sentido, SILVA, Artur Flamínio da - «Hiperandrogenismo». In: Enciclopédia de Direito do Desporto, p. 214. «(...) uma das soluções para evitar as críticas de discriminação de atletas com hiperandroginismo, podia passar pela criação de uma terceira categoria (a categoria neutra), esbatendo-se, assim, a categorização dicotómica de homem/mulher. Nada impede que o Desporto evolua para uma total eliminação de categorias». 
A típica organização das competições desportivas baseada no género feminino ou masculino traduz-se numa forma de discriminação indireta, aferida pelo resultado, relativamente às atletas transgénero femininas ou com diferenças no desenvolvimento sexual, atenta a relevância dos níveis de testosterona que podem determinar uma vantagem real em relação aos atletas cisgénero, considerando as razões de ordem física e fisiológicas que determinam diferenças entre homens e mulheres.

Uma forma de mitigar as vantagens imanentes de ordem genética seria a criação de um sistema de handicap centrado na resposta do corpo ao nível de testosterona efetivo para a prática da modalidade concreta, atendendo a que os níveis de testosterona efetiva possam ser determinantes no resultado ${ }^{162}$.

Todavia, não existindo evidências científicas que sustentem de forma consolidada a manutenção da segmentação binária generalizada, particularmente por referência ao nível de testosterona e de igual forma que a eventual vantagem conferida pelo nível de testosterona seja distinta de qualquer outra vantagem genética natural independentemente da modalidade desportiva concreta, atendendo ao atual resultado material da aplicação do princípio the skill thesis eminentemente discriminatório, a eliminação de categorias por género binário apresenta-se como uma forma de alcançar a igualdade material por via da paridade.

Tendo em vista o desiderato do princípio, em alternativa à segmentação de atletas por sexo anatómico, melhor se afigura a consideração de outros fatores para cada modalidade que, de facto, podem contribuir significativamente para a determinação do vencedor da competição de acordo com o paradigma da justiça desportiva.

Nestes termos, não abdicando da aplicação do princípio the skill thesis e do profícuo resultado inclusivo que ao mesmo se pode assacar, de forma a obstar à segregação das atletas transgénero ou com diferenças no desenvolvimento sexual, entende-se que a criação de um sistema de handicap que considere as vantagens genéticas, fisiológicas e físicas de todos os atletas (cisgénero, transgénero e com diferenças no desenvolvimento sexual) relevantes em cada modalidade desportiva, alcançará o profícuo resultado de mitigar transversalmente as vantagens resultantes da lotaria genética natural ${ }^{163}$.

É, nestes termos, de afastar a opção de criação de uma terceira categoria neutra porquanto, no limite, o resultado de exclusão poder-se-ia verificar nestas circunstâncias por força das atletas não terem nenhuma outra atleta transgénero feminina ou com diferenças de desenvolvimento sexual.

162 BIANCHI, Andria - «Transgender Women in Sports». In: Journal of the Philosophy of Sport, pp. 237-239.

163 BIANCHI, Andria - «Something Got to Give: Reconsidering the Justification for a Gender Divide in Sport». In: Philosophies, p. 6. 
Partindo do conteúdo substantivo da paridade, uma reinterpretação contemporânea permite avançar paulatinamente para a afirmação de que esta existe na medida em que se defenda que a diferença sexual não é decisiva na classificação da espécie humana. $\mathrm{O}$ pressuposto é o de a pessoa não é aquilo que é em função do sexo morfológico ${ }^{164}$.

A eliminação de categorias por referência ao género binário permite obstar a discriminações arbitrárias, designadamente por força do sexo, bem como promove o resultado prosseguido pelo princípio the skill thesis de justiça material.

Se a demarcação da porção a que cada pessoa tem direito no leque de bens disponíveis, leia-se iguais oportunidades de participar nas competições desportivas, porção essa que há de ser rigorosamente igual para todos os indivíduos, não se encontrar adstrita à organizações reducionistas das potencialidades do ser em devir que é a pessoa humana, promove-se um ambiente mais inclusivo e não estigmatizante no desporto que permite o estabelecimento perpétuo de uma participação materialmente igualitária.

Por conseguinte, a possibilidade de se alcançar um equilíbrio entre as diferenças das pessoas e as caraterísticas que lhe são comuns com a eliminação das categorias binárias deve-se, sobretudo, ao facto de a organização das competições encontrar fundamento em caraterísticas especificamente relevantes para a modalidade desportiva concreta.

Um sistema de organização assente neste pressuposto é mais inclusivo, não apenas por acolher as vantagens decorrentes genética natural, mas de igual forma por criar condições materiais de elegibilidade para atletas de género não binário, e que não tenham intenção de recorrer a terapias hormonais ou à cirurgia de afirmação de género, alcançando-se desta forma a definição permanente de uma igualdade material.

De resto, este sistema meritocrático não significará que não se venham a verificar competições em que atletas cisgénero masculino ou feminino competirão com atletas do mesmo género e sexo, contudo o paradigma que presidirá à organização das competições desportivas, com a eliminação total de categorias por referência ao género, será o endereçar as caraterísticas relevantes para a modalidade desportiva para alcançar a justiça real ou de resultado de acordo com as competências físicas e fisiológicas do/a atleta. 


\section{REFERÊNCIAS}

\section{Fontes documentais}

CONSELHO Europeu - Recomendação 2048.

COURT of Arbitration for Sport - «CAS 2014/A/3759, Dutee Chand vs. AFI \& IAAF». [Consult. 22 fevereiro 2020]. Disponivel em https://plawyered.files.wordpress.com/2015/og/dutee-chand-v-athletics-federation-ofindia-af-the-international-association-of-athletics-federations-iaaf.pdf

Diretiva N. ${ }^{0}$ 2004/113/CE. Jornal Oficial da União Europeia. Disponível em https://eur-lex.europa.eu/legalcontent/PT/TXT/PDF/?uri=CELEX:32004Lo113\&from=IT

IAAF - «Eligibility Regulations for the Female Classification (Athlets With Differences of Sex Development)». [Consultado a 22 abril 2020]. Disponível em https://www.sportsintegrityinitiative.com/ wp-content/uploads/2019/05/IAAF-Eligibility-Regulations-for-the-Female-Classi-2-compressed.pdf

Lei N. ${ }^{\circ}$ 14/2008, de 12 de março. Diário da República. N. ${ }^{\circ}$ 51, Série I de 2008-03-12

LEI N. ${ }^{\circ}$ 38/2018, de 7 de agosto. Diário da República. N. ${ }^{\circ} 151$, Série I de 2018-08-07

TRIBUNALEuropeudosDireitosdoHomem- «ProcessoN. ${ }^{\circ} 13343 / 87$. BversusFrance». [Consultadoa12janeiro 2020]. Disponivel em https://hudoc.echr.coe.int/ eng\#\{\%22fulltext\%22:[\% 22|\%2213343/871\%22\%22],\%22do cumentcollectionid2\%22:[\%22GRAND CHAMBER\%22,\%22CHAMBER\%22],\%22itemid\%22:[\%22001-57770\%22]\}

The Yogykarta Principles Plus 10. [Consultado a 17 maio 2020]. Disponivel em https://yogyakartaprinciples. org/principles-en/ypio/

The Yogykarta Principles. [Consultado a 2 maio 2020]. Disponível em https://yogyakartaprinciples.org/

WORLD Health Organization - «International Classification of Diseases». [Consultado a 28 janeiro 2020]. Disponível em https://www.who.int/classifications/icd/en/

CNECV - «Parecer N. ${ }^{\circ}$ 99/CNECV/2017: Relatório e Parecer sobre a Proposta de Declaração Universal sobre Igualdade de Género». [Consultado 17 maio 2020]. Disponbível em https://www.cnecv.pt/pt/ pareceres/parecer-n-0-99-cnecv-2017-sobre-a-proposta-de-declaracao-univers

CONGREGAÇÃO para a Educação Católica - «Homem e Mulher os Criou». Vaticano: [sn], 2019. [Consultado 28 março 2020]. Disponível em http://www.educatio.va/content/dam/cec/Documenti/19_1000_ PORTOGHESE.pdf

IAAF - «Elibibility Regulations for the Female Classification (Athletes With Differences of Sex Development) Explanatory Note». [Consultado 8 maio 2020]. Disponível em https://www.worldathletics. org/news/press-release/questions-answers-iaaf-female-eligibility-reg

INTERNATIONAL Olympic Committee - «IOC Consensus Meeting on Sex Reassignment and Hyperandrogenism November 2015». [Consultado 22 abril 2020]. Disponível em https://stillmed. olympic.org/Documents/Commissions_PDFfiles/Medical_commission/2015-11_ioc_consensus_meeting_on_ sex_reassignment_and_hyperandrogenism-en.pdf

UNESCO - «International Charter of Physical Education, Physical Activity and Sports». [Consultado 26 fevereiro 2020]. Disponivel em https://unesdoc.unesco.org/ark:/48223/pfooo0235409_por

UNESCO - «Unesco's Gender Mainstreaming Implementation Framework for 2002-2007 - Basic Definitions of Key Concepts and Terms». [Consultado 8 março 2020]. Disponível em http:// portal.unesco.org/es/files/14954/10645732009Gender_Mainstreaming_Implementation_Framework.pdf/ Gender+Mainstreaming+Implementation+Framework.pdf

WORLD Health Organization - «WHO/Europe brief - transgender health in the context of ICD-11». [Consultado 3 junho 2020]. Disponivel em https:/www.euro.who.int/en/health-topics/health-determinants/ gender/gender-definitions/whoeurope-brief-transgender-health-in-the-context-of-icd-11 
WORLD Professional Association for Transgender Health - «Standarts of Care for the Health of Transsexual, Transgender, and Gender-Nonconforming People». [Consultado 12 janeiro 2002]. Disponível em https://www.wpath.org/publications/soc

\section{Bibliografia}

AMERICAN Psychiatric Association - «Help With Gender Dysphoria». [Consultado 10 junho 2020]. Disponivel em https://www.psychiatry.org/patients-families/gender-dysphoria/what-is-gender-dysphoria.

ASCENSÃO, José de Oliveira - O Direito. Introdução e Teoria Geral. 13. ${ }^{a}$ ed. Coimbra: Edições Almedina, 2008. ISBN 978-972-40-2443-1.

BARBOSA, Mafalda Miranda; ÁLVAREZ, Tomás Prieto - O Direito ao Livre Desenvolvimento da Personalidade. Coimbra: GestLegal, 2020. ISBN 978-989-8951-321-1.

BASS, Megan; GOZALEZ, Luis J.; COLIP, Leslie; [et. al] - «Rethinking Gender: The Nonbinary Approach». In: AM J Health-Syst Pharm. [sl]. Vol. 75, N. ${ }^{\circ} 22$, (2018), pp. 1821-1823.

BELEZA, Teresa Pizarro - Direito das Mulheres e da Igualdade Social. A Construção Jurídica das Relações de Género. Coimbra: Edições Almedina, 2010. ISBN 978-972-40-4237-4.

BIANCHI, Andria - «Something Got to Give: Reconsidering the Justification for a Gender Divide in Sport». In: Philosophies. [sl]. Vol. 4, N. ${ }^{\circ} 23,(2019)$, pp. 1-13.

BIANCHI, Andria - «Transgender Women in Sports». In: Journal of the Philosophy of Sport. Vol. 44, N. ${ }^{\circ} 2$, (2017), pp. 229-242.

CANOTILHO, J. J. Gomes; MOREIRA, Vital - Constituição da República Portuguesa - Volume 1. $4 \cdot{ }^{\text {a }}$ Edição. Coimbra: Coimbra Editora, 2014. ISBN 978-972-32-2286-9.

CARVALHO, Orlando de - Teoria Geral do Direito Civil. 3. ${ }^{\text {a }}$ edição. Coimbra: Coimbra Editora, 2012. ISBN 978-972-32-2017-9.

COOPER, Emely J. - «Gender Testing in Athletic Competitions - Human Rights Violations: Why Michael Phelps is Praised and Caster Semenya is Chastised». In: The Journal of Gender, Race \& Justice. Vol. 14, N. ${ }^{\circ}$, (2010-2011), pp. 233-264.

COOPER, Jonathan - «Testosterone: "the Best Discriminating Factor"». In: Philosophies. Vol. 4, N. ${ }^{0} 36$. (2019), pp. 1-15.

CORDEIRO, António Menezes - Tratado do Direito Civil Português. Tomo IV. Parte Geral. 5. ${ }^{a}$ ed. Coimbra: Almedina, 2019. ISBN 978-972-40-7897-7.

COWAN, Sharon - «"Gender is No Substitute for Sex”: A Comparative Human Rights Analysis of the Legal Regulation of Sexual Identity». In: Feminist Legal Studies. N. ${ }^{13}$, (2005), pp. 67-96.

GLEAVES, John e LEHRBACH, Tim - «Beyond Fairness: The Ethics of Inclusion for Transgender and Intersex Athletes». In: Journal of The Philosophy of Sport. Vol. 43, N. ${ }^{\circ}$ 2, (2016), pp. 311-326.

GODOY, Gabriel César - «La Identidad de Género Trans: Una Construcción Relacional y Contextualizada (San Luiz, Argentina, 2013-2015)». In: Athenea Digital. Vol. 19, N. 3, (2019), pp. 1-27. ISSN 1578-8946.

HIRSCHBERG, Angelica Lindén - «Female Hyperandrogenism and Elite Sports». In: Endocrine Connections Review. N. ${ }^{\circ}$ 9. (2020), pp. 81-92.

LEE, Peter A.; HOUK, Christopher P.; AHMED, S. Faisal; [et. al.] - «Consensus Statement on Management of Intersex Disorders». In: Pediatrics. N. ${ }^{\circ} 118$, (2006), pp. 488-500.

LEE, Peter A.; NORDENSTRÖM, Arlene; HOUK, P. Christopher P. - «Global Disorders of Sex Development Update since 2006: Perceptions, Approach and Care». In: Hormone Research in Pediatrics. N. $85 / 3$, (2016), pp. 158-180.

MACEDO, Ana - Identidade de Género e Orientação Sexual na Prática Clinica. Lisboa: Edições Sílabo, 2018. ISBN 978-972-618-953-4. 


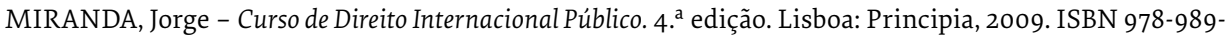
8131-52-1.

MIRANDA, Jorge - Manual de Direito Constitucional. Tomo IV. Direitos Fundamentais. $4 .^{\mathrm{a}}$ ed. Coimbra: Coimbra Editora, 2008. ISBN978-972-32-1613-4.

MIRANDA, Jorge e MEDEIROS, Rui - Constituição Portuguesa Anotada. Tomo I. Coimbra: Coimbra Editora, 2008. ISBN 972-32-1308-7.

MOREIRA, Vital e GOMES, Carla de Marcelino; (Coord.) - «Compreender os Direitos Humanos: Manual de Educação para os Direitos Humanos». [Consult. 28 janeiro 2020]. Disponível em http://pfdc.pgr.mpf. mp.br/atuacao-e-conteudos-de-apoio/publicacoes/direitos-humanos/livro-compreender-os-direitos-humanos

NOVAIS, Jorge Reis - A Dignidade da Pessoa Humana. Volume I. Dignidade e Direitos Fundamentais. $2 .^{a}$ edição. Coimbra: Almedina, 2018. ISBN 978-972-40-7591-4.

NOVAIS, Jorge Reis - A Dignidade da Pessoa Humana. Volume II. Dignidade e Inconstitucionalidade. Coimbra: Almedina, 2016. ISBN 978-972-40-6346-1.

PINTO, Paulo da Mota - Direitos de Personalidade e Direitos Fundamentais - Estudos. Coimbra: GestLegal, 2018. ISBN 978-989-54076-3-7.

POLEZ, Sarah e LEWIS, Anna - «Regulating Genetic Advantage». In: Harvard Journal of Law \& Technology. Vol. 32, N. ${ }^{\circ} 1,(2018)$, pp. 266-298.

RAPOSO, Vera Lúcia - O Poder de Eva. O Princípio da Igualdade no Âmbito dos Direitos Políticos; Problemas Suscitados pela Discriminação Positiva. Coimbra: Edições Almedina, 2004. ISBN 978-972-4019-85-7.

RAPOSO, Vera Lúcia Carapeto - «Paridade, a Outra Igualdade». In: Ciências Jurídicas Civilísticas: Comunitárias; Económicas; Empresariais; Filosóficas; Históricas; Políticas; Processuais. Coimbra: Edições Almedina, 2005.

RAPOSO, Vera Lúcia Carapeto - «Quotas de Género: os prós e os contras de uma solução polémica». In: Direitos Humanos das Mulheres. Coimbra: Coimbra Editora, 2005. ISBN 972-32-1335-4, pp. 111-126.

SANTOS, Heloísa G.; PEREIRA, André Dias - Genética para Todos. De Mendel à Revolução Genómicas do Século XXI: a prática, a ética, as leis e a sociedade. Lisboa: Gradiva, 2019. ISBN 978-989-616-868-1.

SAPPENFIELD, Kourtney - «Adrienne Miller and Jomills Braddock II: Sex Segregation in Sports: Why Separate is Not Equal». In: J Youth Adolescence. California: Praeger, 2016. ISBN 978-1-4408-3810-1, pp. 2479-2482.

SAX, Leonard - «How Common is Intersex? A Response to Anne Fausto-Sterling». In: The Journal of Sex Research. Vol. 39, N. ${ }^{\circ}$ 3. (2010), pp. 174-178.

SCHULTZ, Jamie - «Caster Semenya and the "Question of Too": Sex Testing in Elite Women's Sport and the Issue of Advantage». In: Quest. N. ${ }^{\circ} 63$, (2011), pp. 228-243.

SCHWEND, Amets Suess - «Trans Health Care from a Despathologization and Human Rights Perspective». In: Public Health Reviews. Vol. 41, N. ${ }^{\circ}$ 3, (2020), pp. 1-17.

SILVA, Artur Flamínio da - «Hiperandrogenismo». In: Enciclopédia de Direito do Desporto. Coimbra: GestLegal, 2019. ISBN 978-989-8951-27-4.

TÄNNSJÖ, Torbjörn e TAMBURRINI, Claudio (Coord.) - «Gender Equality and Gene Technology in Sport». In: Genetic Technology and Sport: Ethical Questions. New York: Routledge, 2005, pp. 179-218. ISBN 978-0415-34237-7. 